المجلة الدولية للدراسات التربوية والنفسية

بحث رقم 12

المجلد التاسع، العدد الثاني، 568:552

نيسان (2021)

\title{
فاعلية برنامج قائم على استراتيجيات التعلم التعاوني لتنمية الذكاء العاطفي لدى أطفال الروضة بمدينة مكة المكرمة
}

سوزان صدقة بسيوني'، أمنية عبد القادر الشريف²، دلال هديان الذويبي؛

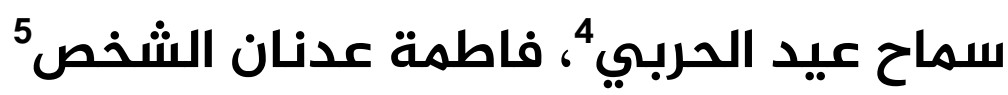

1أستاذ الصحة النفسية والارشاد النفسي- جامعة أم القرى- المملكة العربية السعودية

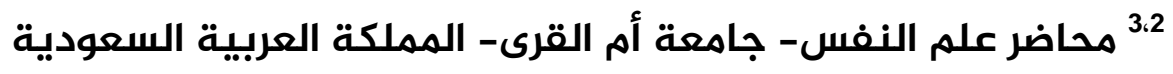
4 محاضر علم النفس- جامعة طيبة- المملكة العربية السعودية 5 باحثة دكتوراه في علم نفس النفة فية التعلم

1 ssbasuoni@uqu.edu.sa, ${ }^{2}$ Monyatee-2008@hotmail.com, ${ }^{3}$ Dalal0855@gmail.com, ${ }^{4}$ samahlayan@gmail.com, ${ }^{5}$ venus-787@hotmail.com

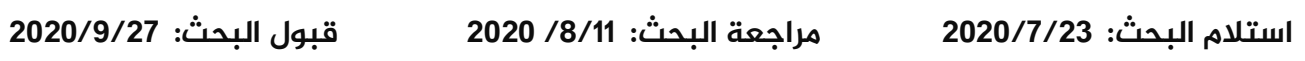

DOI: https://doi.org/10.31559/EPS2021.9.2.12 


\section{فاعلية برنامج قائم على استر اتيجيات التعلم التعاوني لتنمية الذكاء العاطفي لدى أطفال

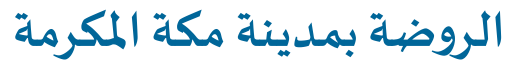

سوزان صهدقة بسيوني1، أمنية عبد القادر الشريف²، دلال هديان الذويبي3، سماح عيد الحربي4، فاطمة عدنان الشخص5 1أستاذ الصحة النفسية والارشاد النفسي- جامعة أم القرى- المملكة العربية السعودية

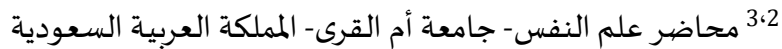

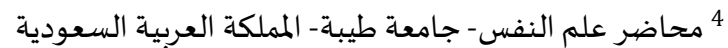

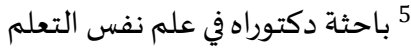

${ }^{1}$ ssbasuoni@uqu.edu.sa,2 Monyatee-2008@hotmail.com,32Dalal0855@gmail.com,

${ }^{4}$ samahlayan@gmail.com, ${ }^{5}$ venus-787@hotmail.com

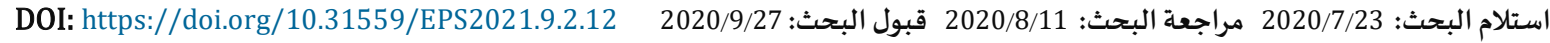

تهدف الدراسة الحالية إلى التعرف على فاعلية برنامج يقوم على استراتيجيات التعلم التعاوني داخل الصف في تنمية الذكاء العاطفي لدى أطفال الروضية بمكة المكرمة، تكونت العينة من (30) طفل وطفلة في المستوى التمهيدي، أعمارهم ما بين (5-6) سنوات، تم اختيارهم بالطريقة العشوائيَّة، طبق عليهم مقياس الذكاء العاطفي قبل وبعد استخدام برنامج يقوم على استراتيجيات التعلم التعاوني: (اللعب

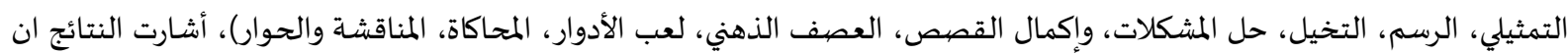
للبرنامج فاعلية في تنمية الذكاء العاطفي لدى عينة الأطفال: ظهرت فروق ذات دلالة إحصائية بين المجموعتين التجريبية والضابطة في

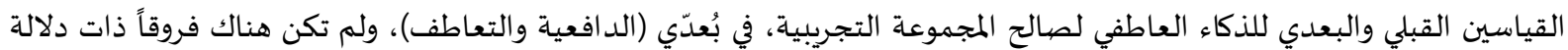
إحصائية في الدرجة الكلية للمقياس وفي أبعاد (الوعي الذاتي بالعواطف، إدارة العواطف، والمهارات الاجتماعية)، وظهرت فروقاً دالة في

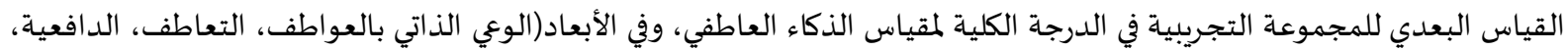

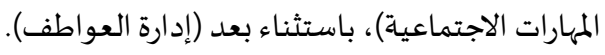
الكلمات المفتاحية: استراتيجيات التعلم التعاوني؛ الذكاء العاطفي؛ أطفال الروضة. المقدمة والإطار النظري:

يتميز عصرنا الحديث بالتطور والتقدم العلمي والتكنولوجي، والازدهار المعرفي، والتغيرات الحديثة والسريعة في شتى مجالات الحياة، وتبعاً لذلك

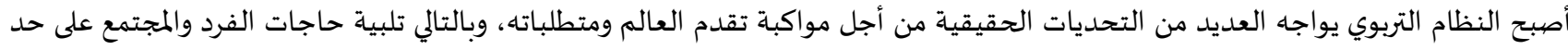

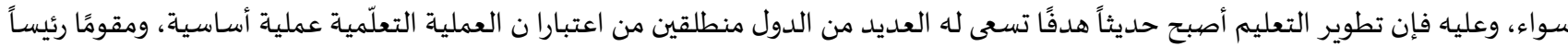

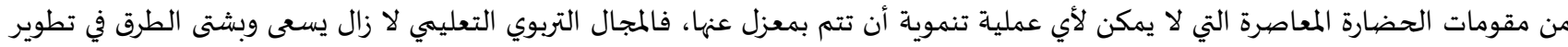

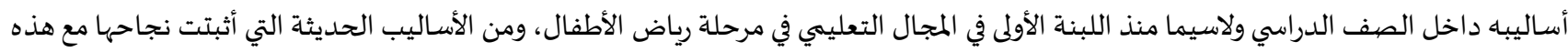

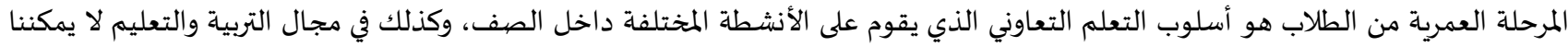

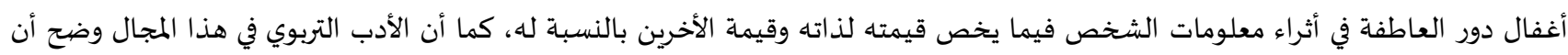


الاستخدام الذكي للعواطف له دور في توجيه السلوك والتفكير والتفاعل مع الأخرين، ومن هذا المنطلق تحاول الدراسة الحالية توظيف أساليب التعلم

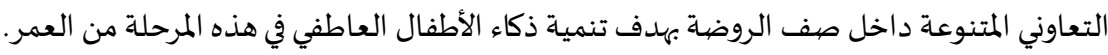

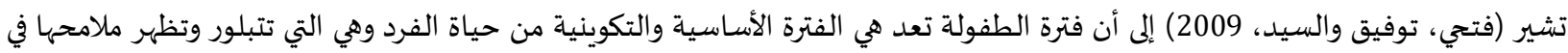

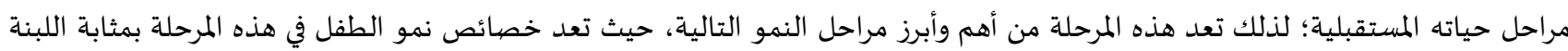

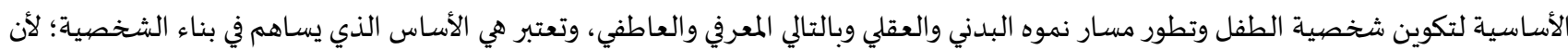

ما يحدث فيها من نمو يصعب تغييره وتعديله فيما بعد.

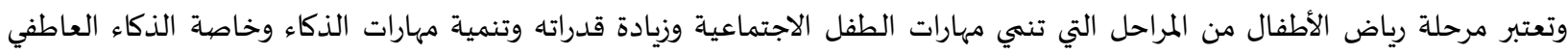
Intelligence Emotional

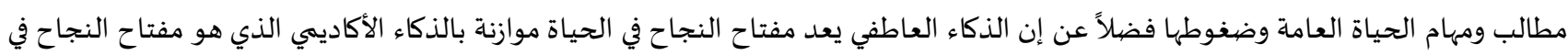

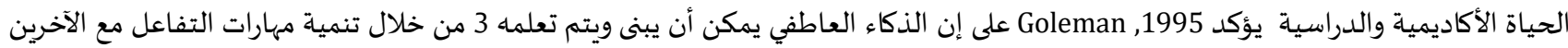
وانه إذا كانت نسبة الذكاء العام على مدى حياة الفرد فان

العاطفي( رحيم وعبد الواحد، 2015).

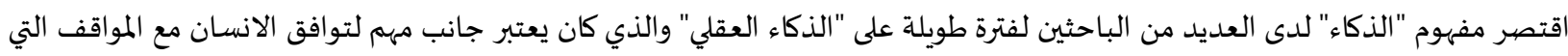

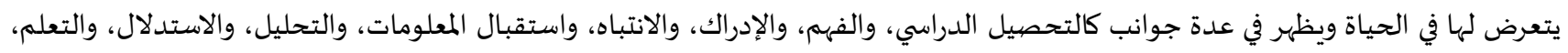

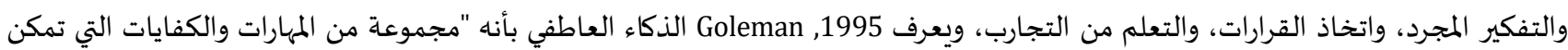

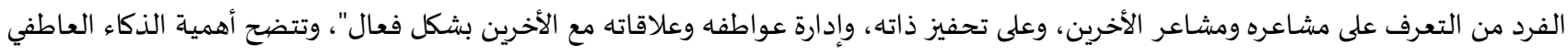

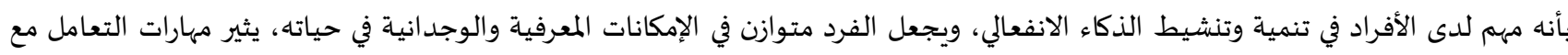

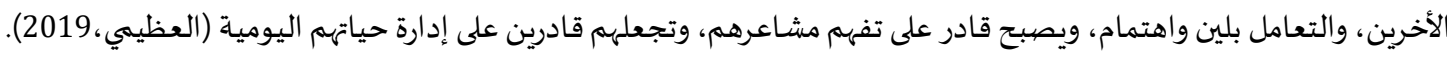

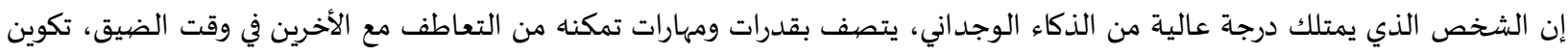

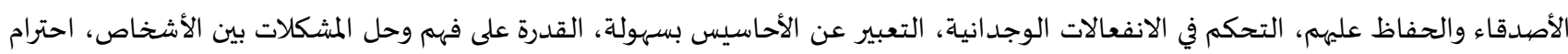

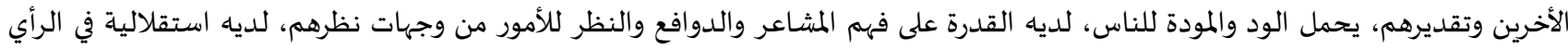

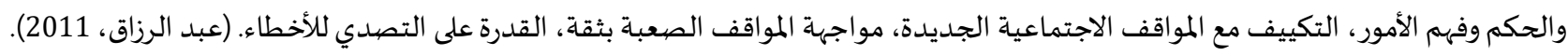

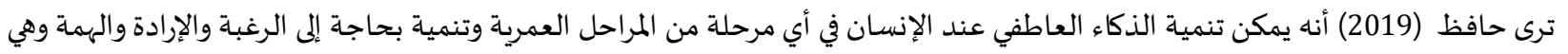

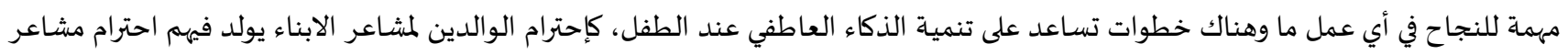

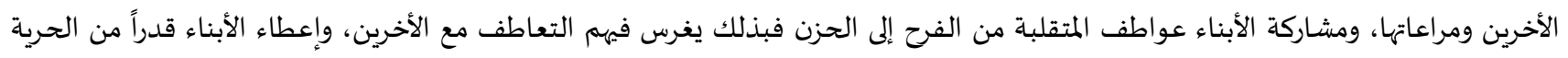

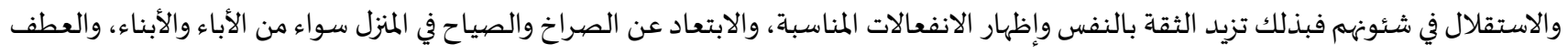

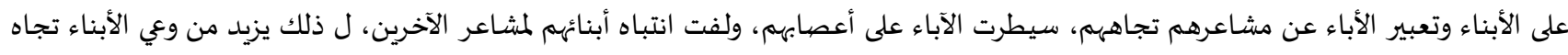

الذكاء العاطفي. أشارت نتائج دراسات وابحاث (جولمان) Goleman في العقل والعاطفة إلى أن هناك عقلين، عقلاً يفكر وآخر يشعر، أي: عقل منطقي، وآخر

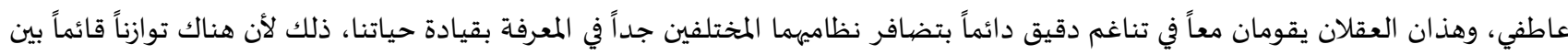

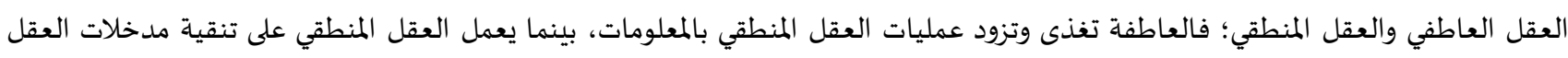

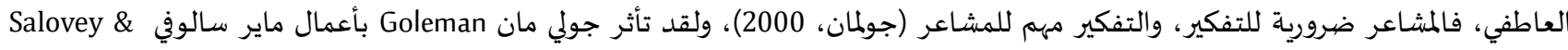

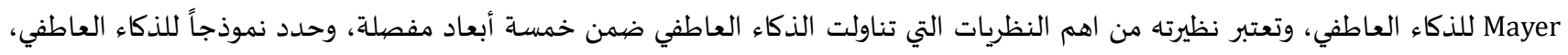

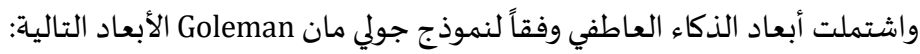

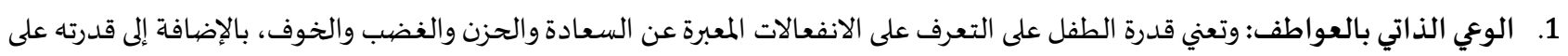
إدراك انفعالاته وتحديدها عند حدوثها، والتعبير عنها. 2.

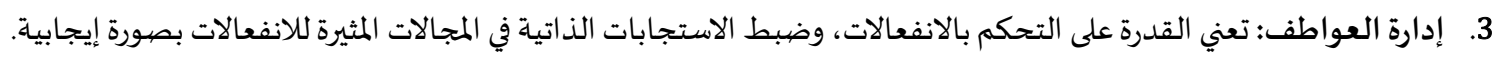

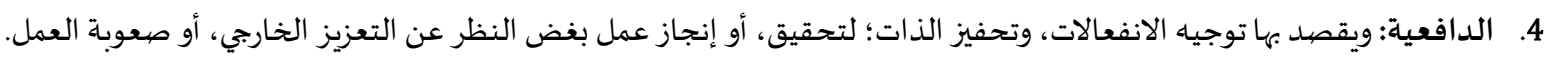

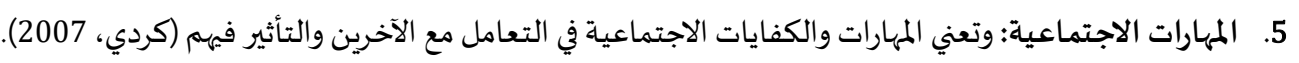


لقد حث التطور التقني والمعرفي الذي حصل في العالم جعل من خبراء التربية والتعليم على البحث عن طرق واستراتيجيات تساعد الأطفال في بناء

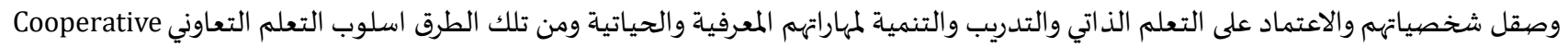

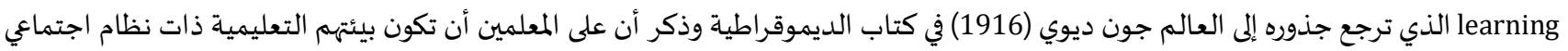

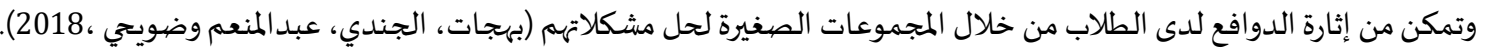

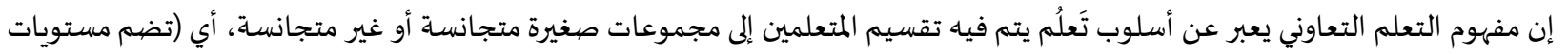

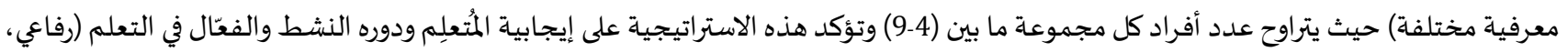

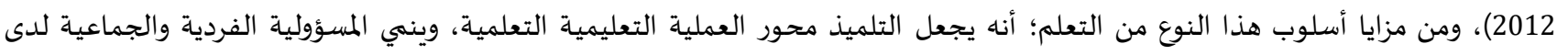

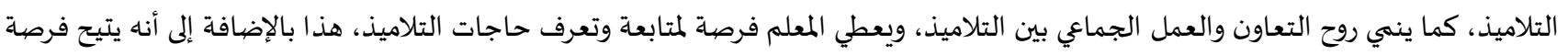

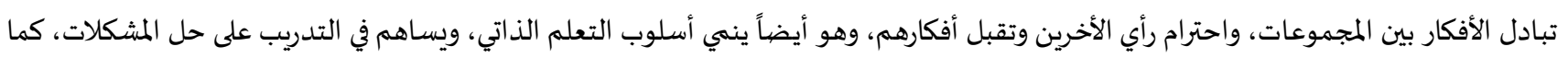

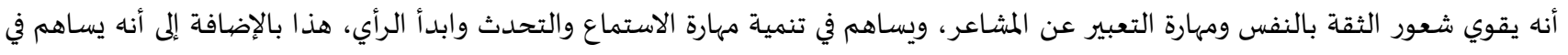

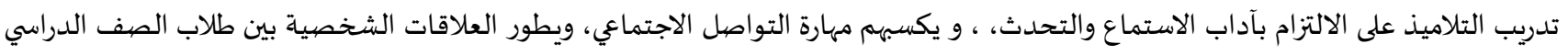

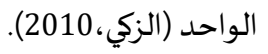

ومن الإستراتيجيات التي اثبتت نجاها مع فئة أطفال الروضة، تلك الاستراتيجيات التي تتضمن التعاون والعمل الجماعي داخل الصف، وقد التد أثبتت

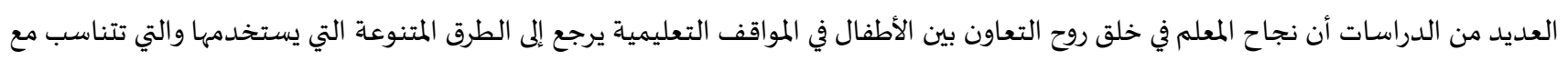

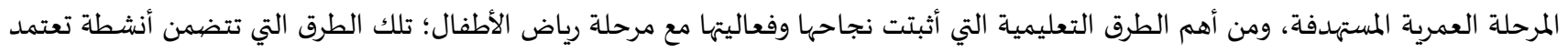

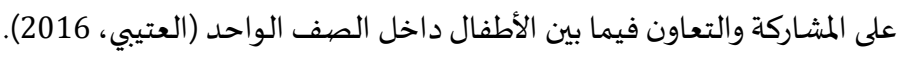

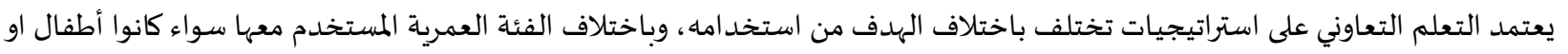

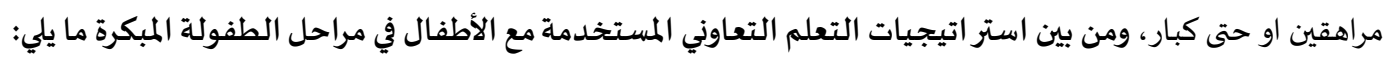

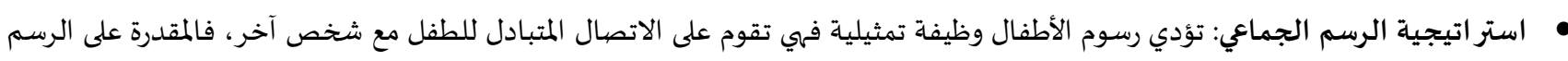

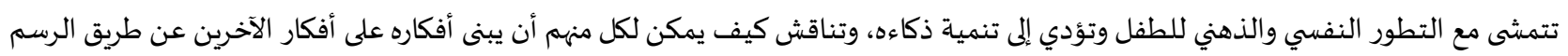
(العياصرة، 2011).

• استر اتيجية التخيل الجماعي: تُستخدم بشكل فعّال مع أطفال الروضة؛؛ لأن تفكيرهم في هذه المرحلة يعتمد على الخيال، فتؤدي إلى الوصهول

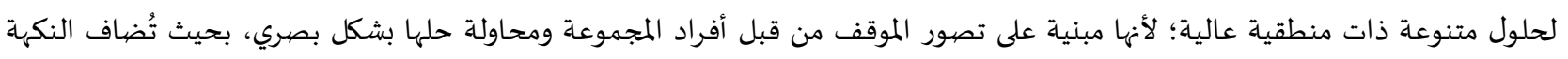

الشخصية عليها (حسنين، 2017).

• استر اتيجية العصف الذهني الجماعي: تتكون جلسة العصف الذهني من جماعة من الأطفال يجلسون حول طاولة مستديرة ويتواصلون تلقائياً

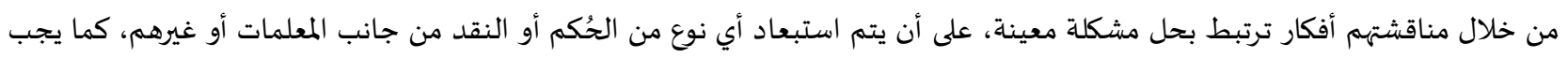
تشجيع التداعي الحر الطليق وتقبل جميع استجابات الأطفال، وكذلك تسجيل كم الاستجابات لا كيفها، وتقبل أي محاولة لتنمية أفكار الأطفال

المقترحة (جاد، 2015).

استر اتيجية الحواروالمناقشـة: أسلوب يستخدم من خلاله أسئلة والأجوبة للوصول إلى الحقيقة، وتكسب الطفل القدرة على النقد البناء وهو وسيلة للتفكير الجيد واكتساب المعلومات وتحقق أهداف الحوار والمناقشة من خلال التمييز بين الحقيقة والرأي وتعبير الطالب عن رأيه بالقبول

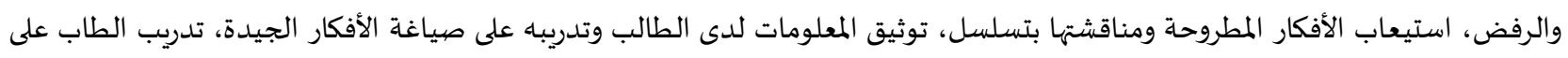

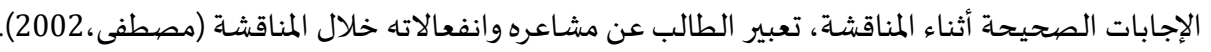

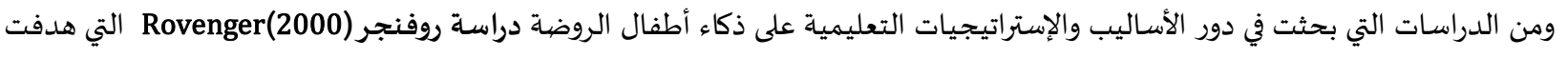

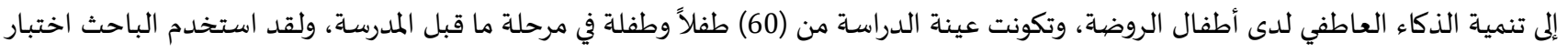

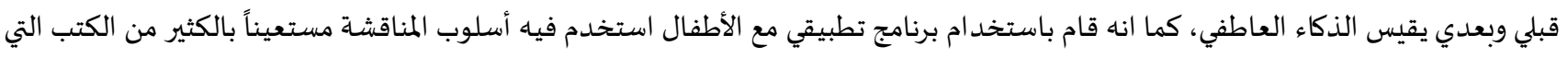

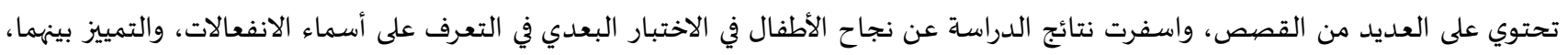

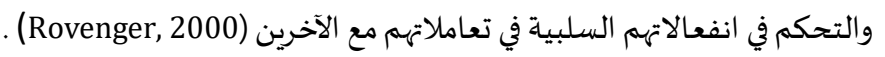

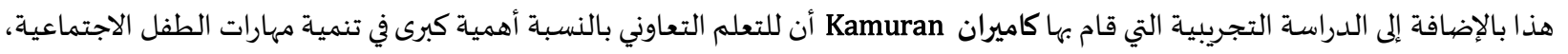

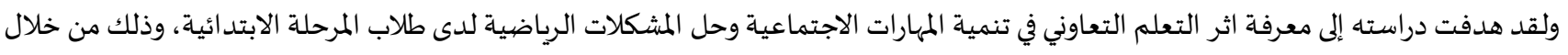

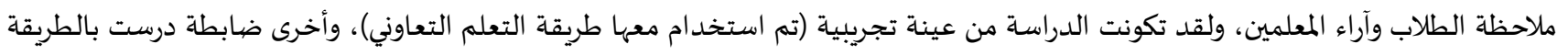


التقليدية، وأظهرت نتائج الدراسة أنه ظهر لدى الأطفال في المجموعة التجريبية تقدم في المهارات الاجتماعية كالتعاون والمسؤولية الفردية داخل الفريق الماريق

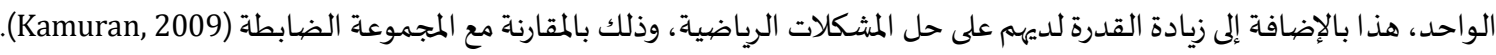

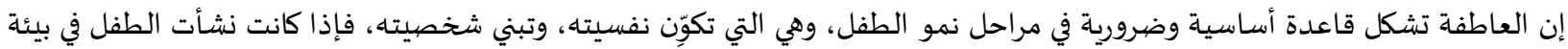

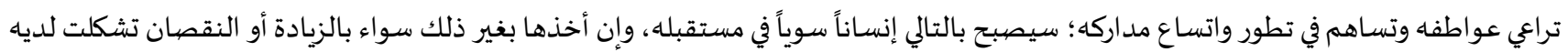

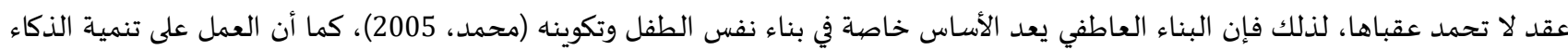
العاطفي لدى الأطفال في المراحل المبكرة من الطفولة يعتبر ضرورة ملحة لتنمية إمكانياتهم العقلية والمعرفية والانفعالية والسلوكية ، لمساعدتهم لاحقاً

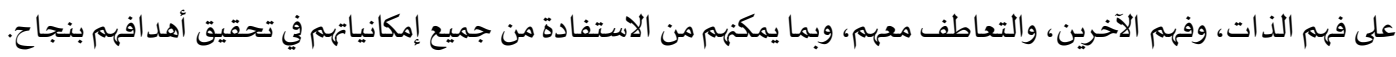

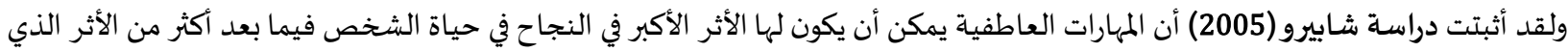

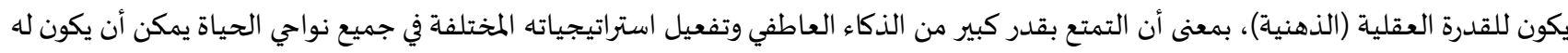

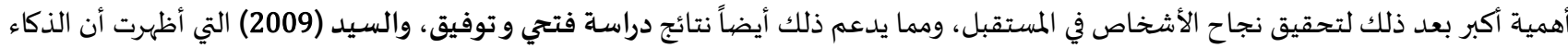

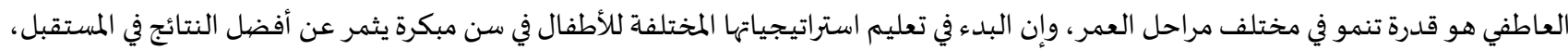

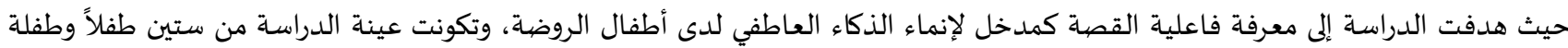

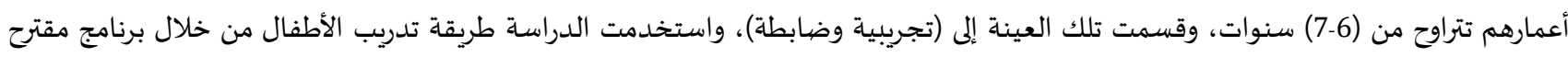

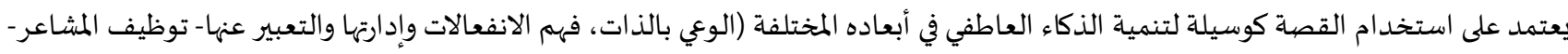

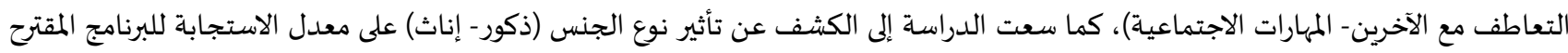

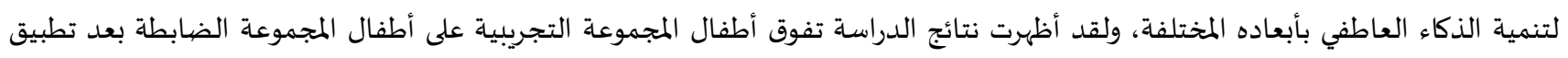
البرنامج المستخدم برواية القصة.

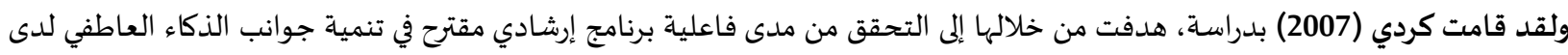

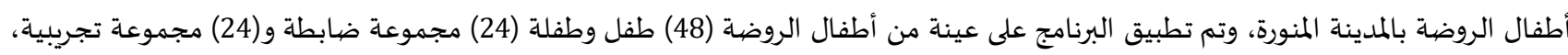

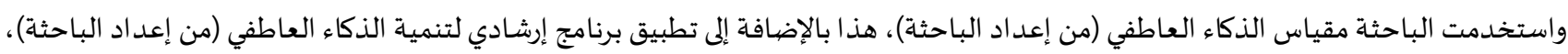

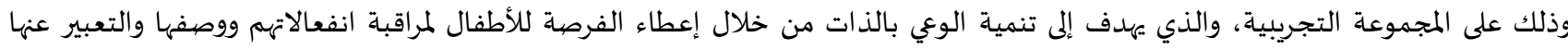

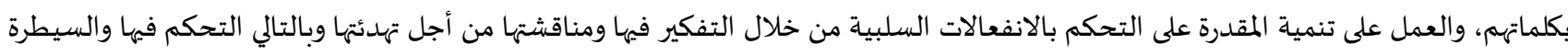

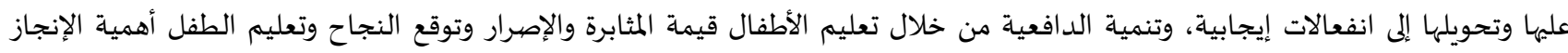

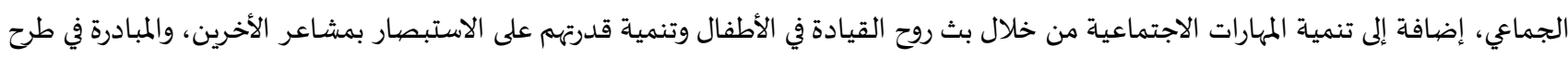

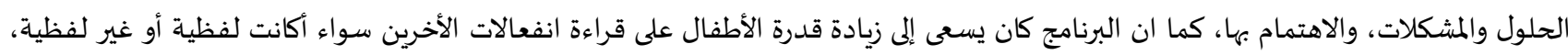

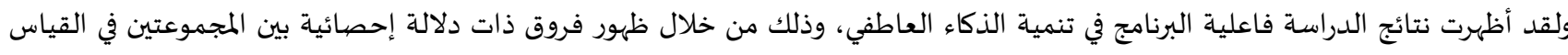

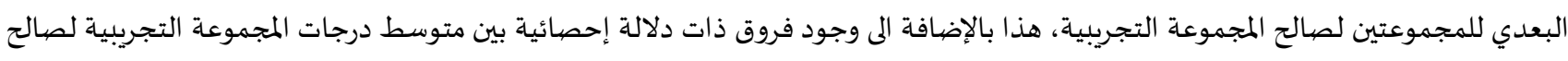

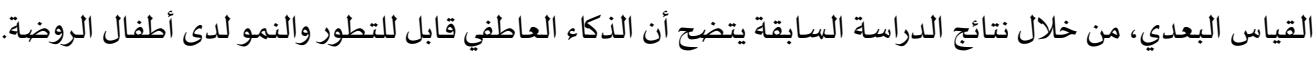

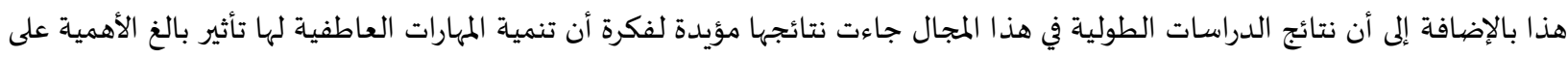

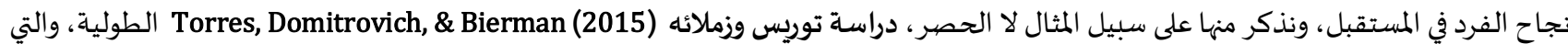

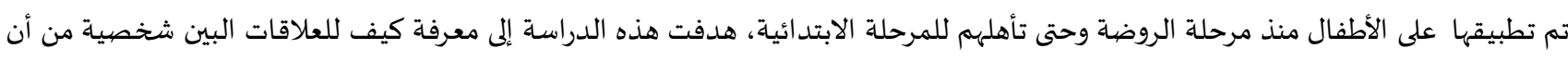

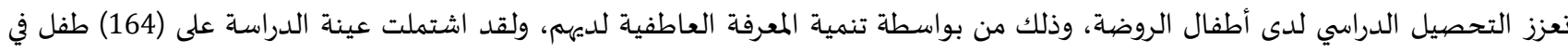

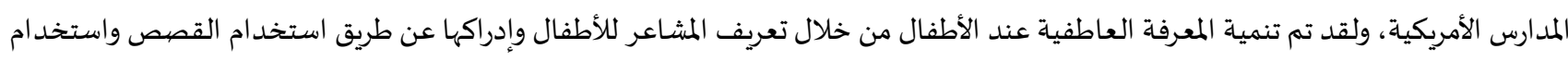

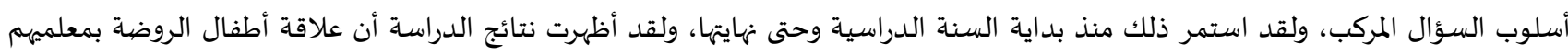

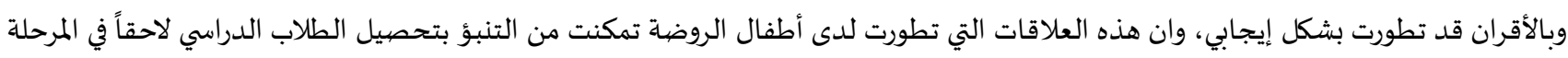
الابتدائية.

ولقد نجحت العديد من الدراسات في توظيف استراتيجيات مختلفة من الأنشطة داخل صفوف مرحلة رياض الأطفال اللعب وسرد القصص

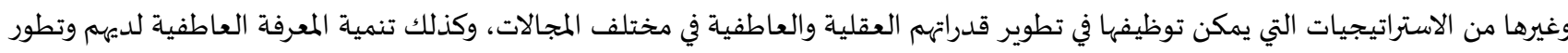

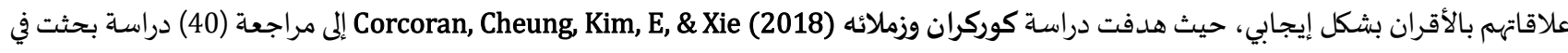

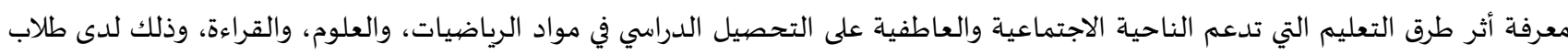
الروضة وطلاب المرحلة الابتدائية والذين بلغ إجمالي عددهم عبر تلك الدراسات $(57,755)$ طالب، ولقد ركزت الدراسة على العلاقات الارتباطية بين 
المميزات والمعلومات الناتجة عن التعليم المدرسي الذي يعتمد في طريقته على النواحي الاجتماعية والعاطفية، ولقد توصلت نتائج هذه المراجعة

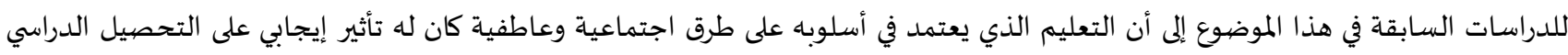

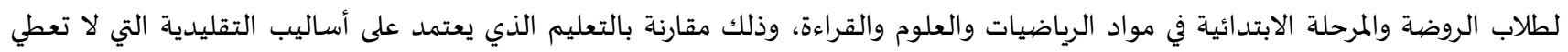
الجوانب الاجتماعية والعاطفية اهتماماً خاصاً.

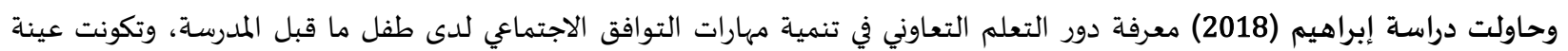
الدراسة من أطفال الروضاة في مدينة الإسكندرية بمصر، واستخدم الباحث فيها مقياس يقيس مهارات التوافق الاجتماعي لدى طفل ماسي ما قبل المدرساة،

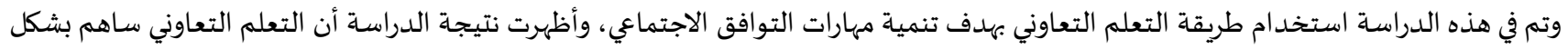

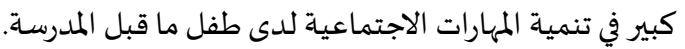

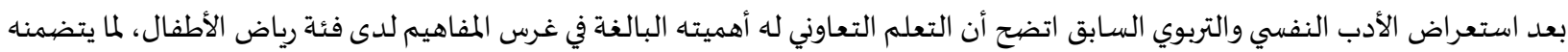
من أساليب واستراتيجيات متنوعة شيقة وجذابة للأطفال في هذه المرحلة العمرية، الأمر الذي يشجع على استثمار هذا الأسلوب العلمي في تنمية ذكائهم

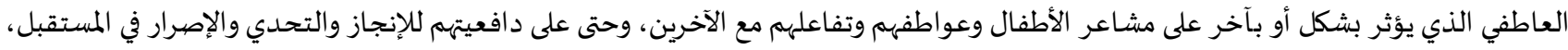

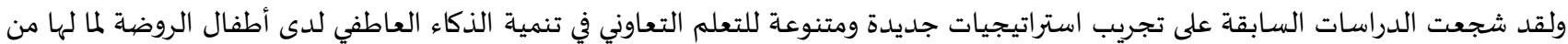

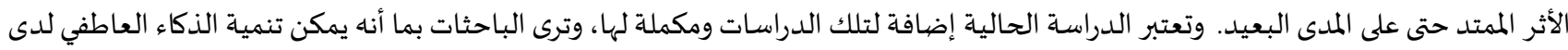

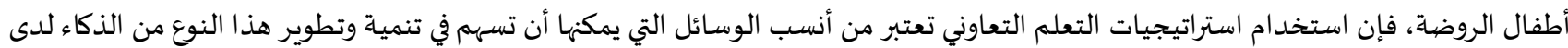
الأطفال الصغار؛ وذلك لما تتمتع باء من مزايا وخصائص تجذب اهتمام الطفل، وتنسجم مع خصان إنسائص نموهم، وتعد فكرة اختبار وتجريب إستراتيجيات

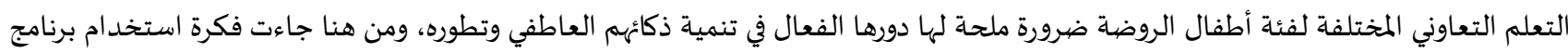

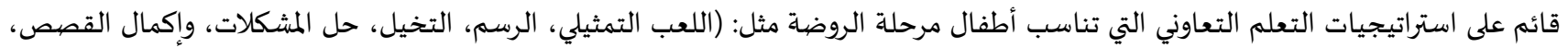

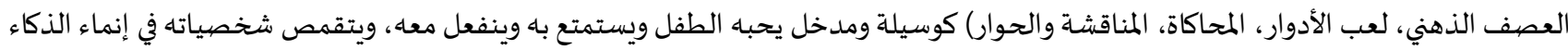

العاطفي لدياء بطريقة غير مباشرة جذابة ومشوقة.

فروض الدراسـة:

1. توجد فروق ذات دلالة إحصائية بين متوسطات درجات المجموعة الضابطة ومتوسطات درجات المجموعة التجريبية على مقياس الذكاء العاطفي

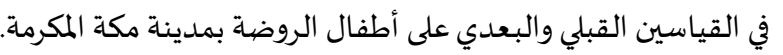
2. توجد فروق ذات دلالة إحصائية بين متوسطي درجات القياسين القبلي والبعدي للمجموعة التجريبية على مقياس الذكاء العاطفي لدى اطفال الروضية بمدينة مكة المكرمة.

أهداف الدراسـة: تهدف الدراسة الحالية إلى التعرف على فاعلية برنامج قائم على استراتيجيات التعلم التعاوني لتنمية الذكاء العاطفي لدى أطفال الروضية بمنطقة مكة المكرمة، ويمكن ذكر أهم تلك الأهداف على النحو التالي:

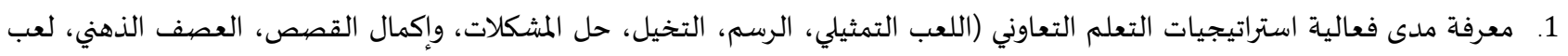

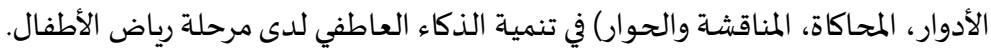

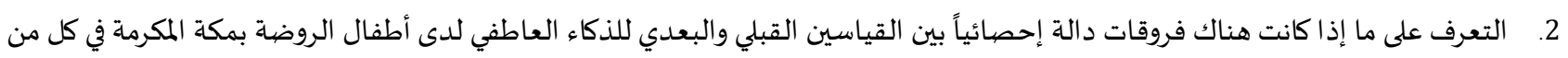

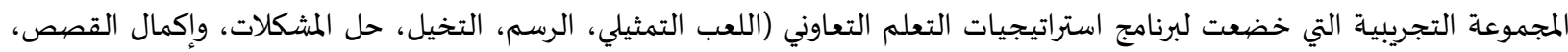
العصف الذهني، لعب الأدوار، المحاكاة، المناقشة والحوار)، والمجموعة الضيابطة التي لم تخضيع لأي برنامج.

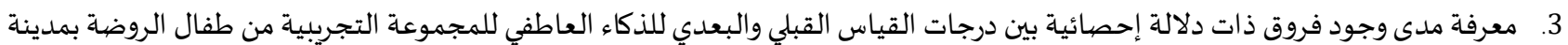

مكة المكرمة.

أهمية الدراسـة: الأهمية النظرية: 1. تعد هذه الدراسة إثراءً للأطر النظرية المتعلقة بأهمية استخدام استراتيجيات التعلم التعاوني لتنمية الذكاء العاطفي لدى الأطفال والدور الذي يلعباء في توافق الطفل مع نفسه ووالدياه وإخوته وأقرانه وبيئته وزملائه في الروضية، ومن ثم مساعدته على النجاح في المستقبل في شتى مجالات 
2. تقديم برنامج قائم على استراتيجيات التعلم التعاوني حيث أنه في حدود علم الباحثات لم يتبين هناك أي برنامج يقوم على استراتيجيات لتمية الذكاء العاطفي لدى فئة رياض الأطفال.

الأهمية التطبيقية: 1. توجياء نظر الجهات المسؤولة عن وضع وتخطيط مناهج رياض الأطفال إلى أهمية إدماج وتضيمين استراتيجيات التعلم التعاوني المتنوعة والتي

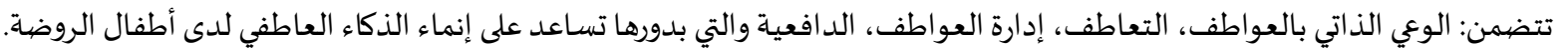

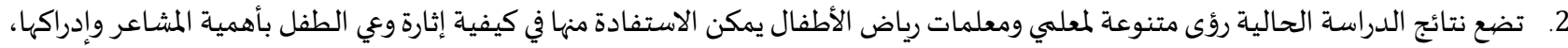
وإداراتها، وإدراك مشـاعر الآخرين، والتعامل معها والتعاطف الوجداني في مختلف المواقف الحياتية، ومن ثم القدرة على حل المشكلات التي

تواجهاه.

3. تعطي المهتمين بضرورة تفعيل استراتيجيات التعلم التعاوني لتنمية الذكاء العاطفي لدى أطفال الروضية. 4. إفادة المختصين في مجال تدريس رياض الأطفال في وضيع الحلول الملائمة للتغلب على المعوقات التي تواجهات تطبيق استراتيجيات التعلم التعاوني.

حدود الدراسـة: التزمت الدراسـة بالمحدددات التالية: الحد الموضوعي: اقتصرت هذه الدراسة على متغيرات البحث وهي فاعلية برنامج قائم على استراتيجيات التعلم التعاوني لتنمية الذكاء العاطفي لدى أطفال الروضة بمكة المكرمة. الحد الزماني: طبقت الدراسة في الفترة من 5 نوفمبر إلى 5 ديسمبر 2019.

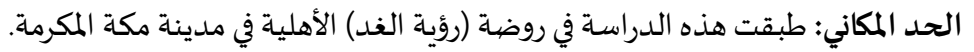

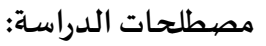

الفاعلية:

لغةة: مأخوذة من 》الفعل فَّل، وهو كناية عن كل عمل متعد أو غير متعده (ابن منظور، 2004، 201). وتعرف الفاعلية اصطلاحاً: الفاعلية بأنها: "مدى قدرة أي معالجة على على تحقيق أهداف تعليمية محددة، وبلوغ مخرجات معرفية مرجوة"(صبري، 2002،

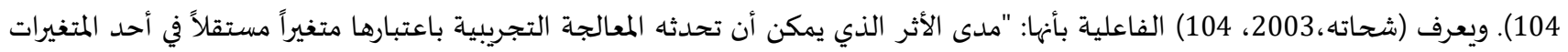
التابعة". التعريف لإجر ائي للفاعلية: الأثر الإيجابي الذي يظهر في نمو الذكاء العاطفي لدى أطفال الروضاة نتيجة استخدام برنامج يتضمن على استراتيجيات

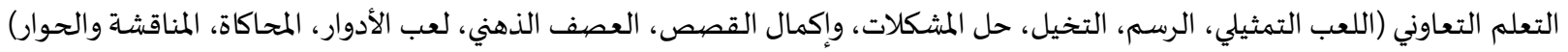
استر اتيجيات التعلم التعاوني: تعرف استراتيجيات التعلم التعاوني على أنها: استراتيجية تدريس يتم فهها استخدام الجماعات الصغيرة وتضيم كل

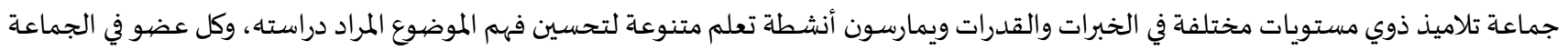

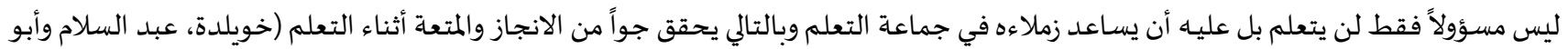

حديدة 2017، 208).

التعريف الإجر ائي لاستر اتيجيات التعلم التعاوني: تعرف الباحثات استراتيجيات التعلم التعاوني المستخدمة في برنامج تنمية الذكاء العاطفي لدى

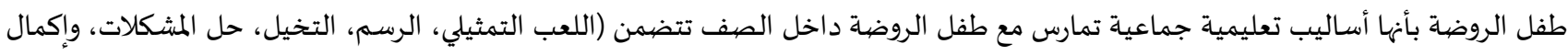

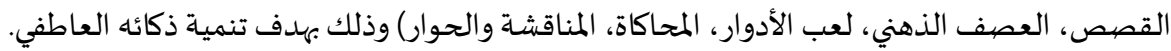

الذكاء العاطفي:

يعرف الذكاء العاطفي بأنه: "عن مجموعة الصفات الشخصية والاجتماعية والوجد انية التي تمكن الفرد من تفهه مشاعره وانفعالاته وتسميتها وإدارتها، وتفهم انفعالات الآخرين والتعاطف معهم، فهو القدرة على فهم المشاعر الذاتية ومشاعر الآخرين والتعامل معهم وتكوين علاقات معهم والتعبير عن

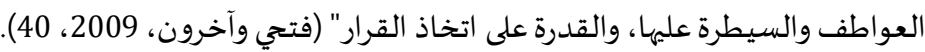
التعريف الإجر ائي لذكاء طفل الروضة العاطفي: يُعرف الذكاء العاطفي إجرائياً بأنها مجموع درجات الطفل على المقاييس الفرعية الخمسة لمكونات

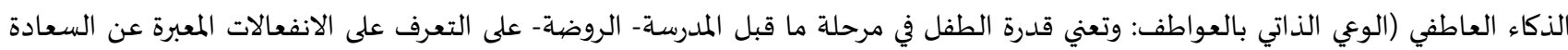
والحزن والغضب والخوف، بالإضافة إلى قدرته على إدراك انفعالاته وتحديدها عند حدوثها، والتعبير عنها، التعاطف: ويقصد باه الحساسية لمشاعر

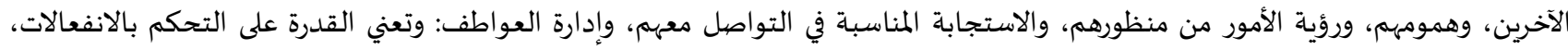
وضبط الاستجابات الذاتية في المجالات المثيرة للانفعالات بصورة إيجابية، الدافعية: ويقصديد بها توجياء الانفعالات، وتحفيز الذات؛ لتحقيق، أو إنجاز 
عمل بغض النظر عن التعزيز الخارجي، أو صعوبة العمل، والمهارات الاجتماعية: وتعني المهارات والكفايات الاجتماعية في التعامل مع الآخرين والتأثير فيهم (كردي، 2007).

\section{منهج الدراسة وإجراءات التطبيق:}

منهبج الدراسة:

تم استخدام المنهج الشبة التجريبي نظراً لملائمته لطبيعة البحث، والذي تضمن مجموعتين أحدهما تجريبية (تم تطبيق استراتيجيات التعلم التعاوني عليها)، والأخرى ضابطة تستخدم الطرق التقليدية في التعلم، وتم إجراء القياسين القبلي والبعدي لمقياس الذكاء العاطفي لكل من المجموعتين.

مجتمع الدراسـة:

تكون مجتمع الدراسة من جميع أطفال الروضة في منطقة مكة المكرمة في رياض الأطفال والذين هم على مقاعد الدراسة في الفصل الدراسي الأول

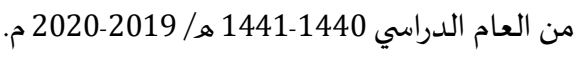

عينة الدراسة:

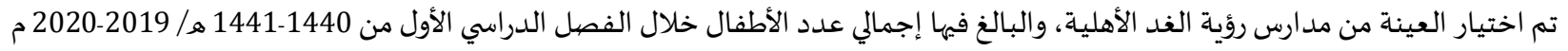

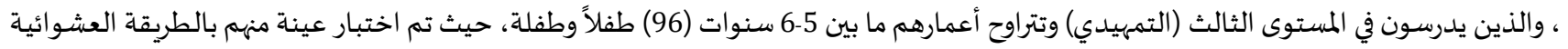

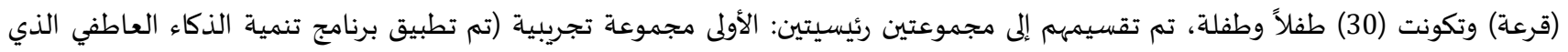

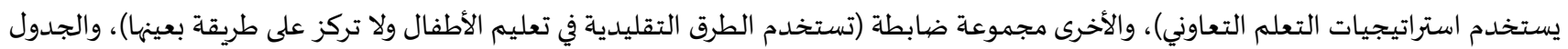
(1) يوضح توزيع العينة.

\begin{tabular}{|c|c|c|}
\hline \multicolumn{3}{|c|}{ جدول (1) توزيع أفراد العينة ن=30 } \\
\hline 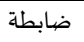 & تجريبية & الجنس / المجموعة \\
\hline 10 & 6 & ذ ذكور \\
\hline 5 & 9 & 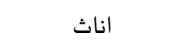 \\
\hline 15 & 15 & المجموع \\
\hline
\end{tabular}

أدوات الدراسـة:

تكونت أدوات الدراسة من قسمين، تمثل القسم الأول في مقياس الذكاء العاطفي من إعداد كردي (2007)، في حين اشتمل القسم الثاني من

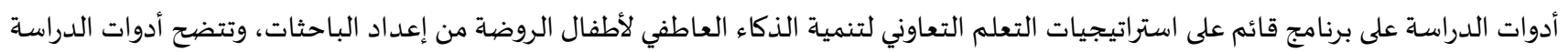
من خلال التفصل التالي: القسم الأول: مقياس الذكاء العاطفي لأطفال الروضئ

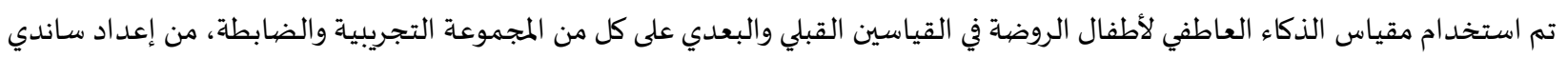
فاروق كردي (2007)، ويتكون المقياس من خمس أبعاد فرعية تناولت مهارات الذكاء العاطفي بالاعتماد على نظرية جولمان Goleman، بحيث تم تحديد أبعاد الذكاء العاطفي كالآتي:

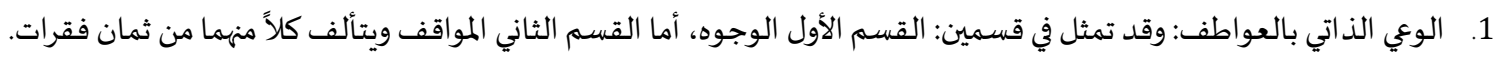
2. 3. إدارة العواطف: ويضم هذا الفرع ثلاث قصص تصف موقفاً افتراضياً حدث مع الطفل ويطلب من الطفل أن يحدد ماذا يفعل من خلال الإجابة على ثلاثة أسئلة. 4.

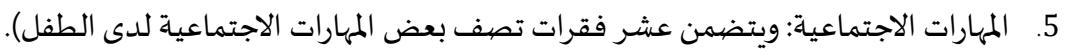

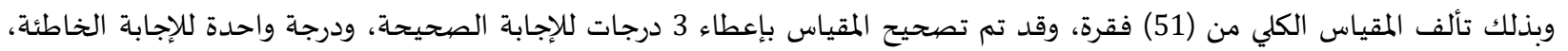

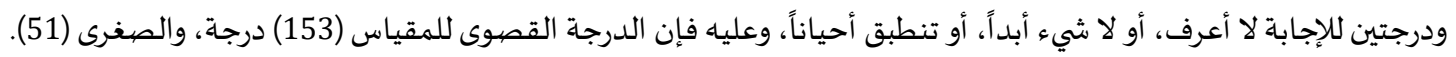
الخصائص السيكو مترية لمقياس الذكاء العاطفي (كردي، 2007) في بيلته الأصلية:

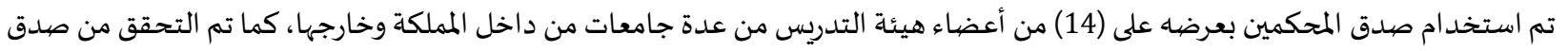

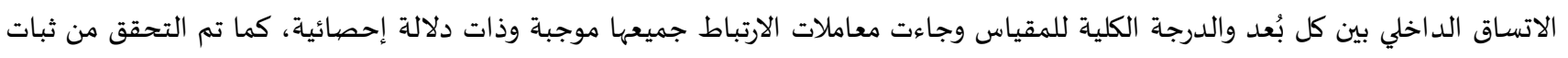
المقياس بإعادة التطبيق، ومعامل التجزئة النصفية وقد أشـارت قيم معاملات الثبات إلى صلاحية المقياس للتطبيق، مما يعطى الثقة في نتائجه 
واستخدامها في هذا البحث الذي يتم تطبيقه على فئة رياض الأطفال وفي البيئة السعودية وهما يماثلان للفئة العمرية والبيئة الأصلية للعينة التي تم

تقنين المقياس عليها.

\section{صبدق مقياس الذكاء العاطفي (كردي، 2007) في البحث الحالي المهي}

صدل الاتساق الداخلي:

تم التحقق من الاتساق الداخلي لمقياس الذكاء العاطفي في الدراسـة الحالية بحساب معاملات الاتساق الداخلي لها، باستخدام معامل الارتباط لبيرسون (Pearson-r) بين كل بعد وبين الدرجة الكلية للمقياس من خلال التطبيق على عينة استطلاعية عددها (37) طفلاً وطفلة، كما هو موضح في بهاهي

جدول (2):

جدول (2): معاملات الارتباط بين درجة كل بعد والدرجة الكلية للمقياس ن(37)

\begin{tabular}{|c|c|c|}
\hline الدلالة & معامل الارتباط بالدرجة الكلية & 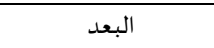 \\
\hline 0.01 & 0.901 & الوعي الذاتي بالعواطف \\
\hline 0.01 & 0.499 & التعاطف \\
\hline 0.01 & 0.751 & إدارة العواطف \\
\hline 0.05 & 0.366 & الدافعية \\
\hline 0.01 & 0.660 & المهارات الاجتماعية \\
\hline
\end{tabular}

يتضح من الجدول السابق أن قيم معاملات الارتباط جاءت جميعها موجبة وذات دلالة إحصائية عند مستوى دلالة (0.05) و(0.01) مما يدل على تمتع مقياس الذكاء العاطفي بدلالات صدق مقبولة لتحقق أهداف الدراسـة الحالية.

ثبات مقياس الذكاء العاطفي في الدراسـة الحالية: مقاء

تم التحقق من ثبات المقياس في الدراسة الحالية، باستخدام معامل التجزئة النصفية، كما هو موضح في جدول (3):

جدول (3): معاملات الارتباط بين درجة كل بعد والدرجة الكلية للمقياس ن (37)

\begin{tabular}{|c|c|}
\hline معامل الثبات باستخدام التجزئة النصفية & 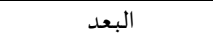 \\
\hline 0.647 & الوعي الذاتي بالعواطف \\
\hline 0.600 & التعاطف \\
\hline 0.643 & إدارة العواطف \\
\hline 0.600 & 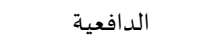 \\
\hline 0.684 & المهارات الاجتماعية \\
\hline
\end{tabular}

يتضح من جدول (3) أن جميع أبعاد مقياس الذكاء العاطفي والمقياس ككل تتمتع بمعاملات ثبات مقبولة، مما يدل على صلاحية تطبيقه في الدراسة الحالية.

القسم الثاني: برنامج قائم على استر اتيجيات التعلم التعاوني لتنمية الذكاء العاطفي لأطفال الروضية

قامت الباحثات بإعداد برنامج قائم على استراتيجيات التعلم التعاوني يهدف إلى تنمية الذكاء العاطفي لدى أطفال الروضية، وذلك بعد الاطلاع

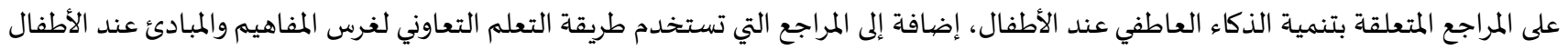
(السرسى، 2007؛ الحارثي، 2010؛ إبراهيم، 2011؛ عبد المعطي، 2000)، تم تطبيق البرنامج على النحو الآتي:

تم عرض البرنامج على خمسة محكمين متخصصين في مجال علم النفس وطرق التدريس وتقنيات التعلم من جامعات مختلفة بالمملكة العربية

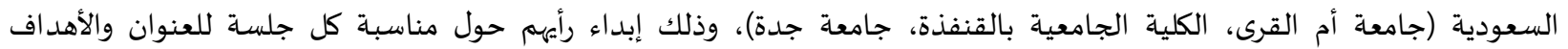

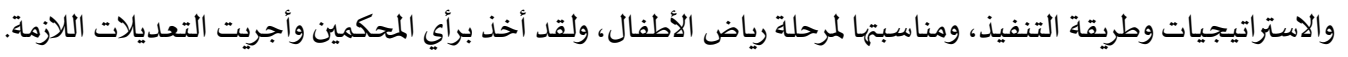

اشتمل البرنامج على ثماني جلسات لأطفال الروضاة، بمعدل جلستين كل أسبوع، لمدة (40) دقيقة للجلسة الواحدة تتضمن فترة راحة لمدة (5)

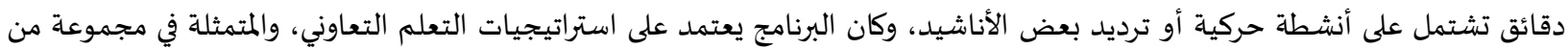
الإجراءات والممارسات التي تم التخطيط لها ويقوم بها الطفل داخل الصف الدراسي. همممت هذه الممارسات بشكل بسيط يتناسب مع مستوى نضج الأطفال واهتماماتهم، بحيث تنوعت الاستراتيجيات ما بين معرفية وفنية وقصصية وحركية. تم اختيار الأطفال من صفين من صفوف التمهيدي في مجموعتين تجريبية وضابطة، وتم تطبيق المقياس قبلياً على المجموعتين باختيار بعض الأطفال عشوائياً. 
تطبيق البرنامج القائم على استراتيجيات التعلم التعاوني لتنمية الذكاء العاطفي على أطفال المجموعة التجريبية والمكون من ثماني جلسات بمعدل جلستين في الأسبوع، بتقسيم الأطفال إلى مجموعة مكونة من (3-4) أطفال، وبعد الانتهاء من تطبيق البرنامج (جدول، 4). إجراء التطبيق البعدي على المجوعتين التجريبية والضابطة.

جدول(4): جلسات البرنامج التدرببي القائم على استر اتيجيات التعلم التعاوني لتنمية الذكاء العاطفي لأطفال الروضة

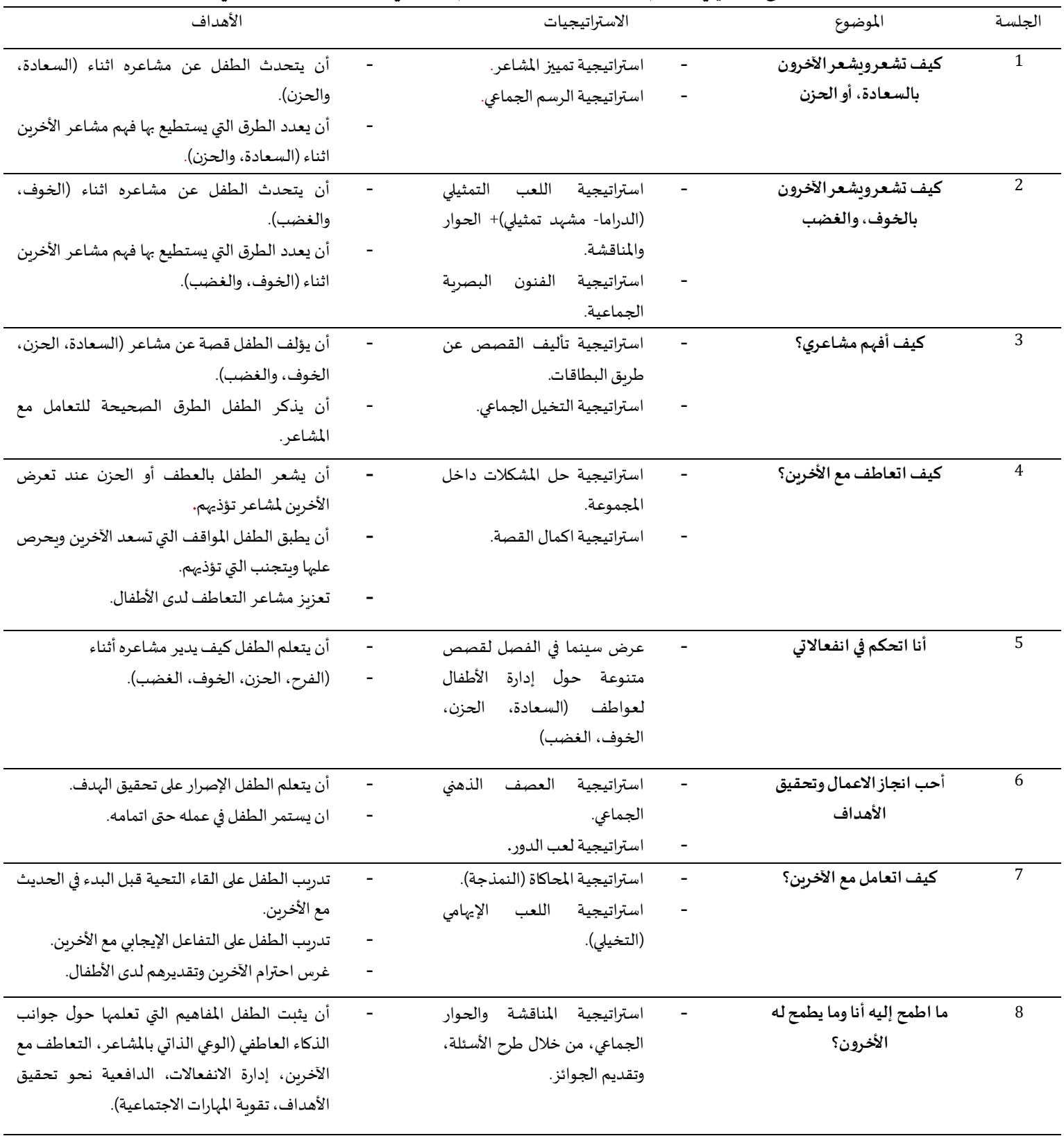

نتائج الدراسة ومناقشتها:

لفحص فرضيات الدراسة تم حساب المتوسطات والانحرافات المعيارية، واختبار (ت) لعينتين مستقلتين، ولعينتين مرتبطتين، وكان ذلك على

النحو التالي:

الفرض الأول: توجد فروق ذات دلالة إحصيائية بين متوسطات درجات المجموعة الضيابطة ومتوسطات درجات المجموعة التجريبية على مقياس

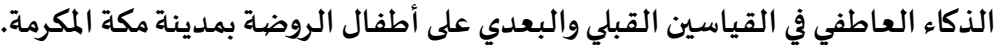
للتحقق من صحة هذا الفرض تم استخراج المتوسطات الحسابية والانحرافات المعيارية لدرجات أفراد عينة الدراسة في المجائية المبموعتين: التجريبية والضابطة على القياسين القبلي والبعدي لمقياس الذكاء العاطفي (كردي، 2007)، كما تم استخدام اختبار (ت) للفروق بين المتوسطات، وجاءت النتائج كما هو موضيح في الجدول التالي: 
جدول (5): نتائج اختبار(ت) بين المتوسطات المستقلة للعينتين التجريبية والضيابطة في القياسين القبلي والبعدي

\begin{tabular}{|c|c|c|c|c|c|c|c|}
\hline الدلالة & درجة الحرية & قيمة (ت) & الانحراف المعياري & المتوسط & المجموعة & البعد & القياس \\
\hline \multirow[t]{2}{*}{0.230} & 28 & 1.227 & 4.51 & 34.26 & التجريبية قبلي & الوعي الذاتي & القبلي \\
\hline & & & 3.45 & 36.06 & الضابطة قبلي & بالعواطف & \\
\hline \multirow[t]{2}{*}{0.775} & 28 & 0.289 & 1.83 & 18.73 & التجريبية قبلي & التعاطف & \\
\hline & & & 1.60 & 18.92 & الضابطة قبلي & & \\
\hline \multirow[t]{2}{*}{0.842} & 28 & 0.201 & 2.28 & 22.30 & التجريبية قبلي & ادارة العواطف & \\
\hline & & & 2.29 & 22.13 & الضابطة قبلي & & \\
\hline \multirow[t]{2}{*}{1.00} & 28 & 0.000 & 1.35 & 15.40 & التجريبية قبلي & الدافعية & \\
\hline & & & 1.35 & 15.40 & الضابطة قبلي & & \\
\hline \multirow[t]{2}{*}{0.196} & 28 & 1.325 & 4.50 & 19.13 & التجريبية قبلي & المهارات الاجتماعية & \\
\hline & & & 2.32 & 20.86 & الضابطة قبلي & & \\
\hline \multirow[t]{2}{*}{0.371} & 28 & 912.- & 8.67 & 110.38 & التجريبية قبلي & الدرجة الكلية & \\
\hline & & & 5.04 & 112.92 & الضابطة قبلي & & \\
\hline \multirow[t]{2}{*}{0.334} & 28 & 0.984 & 6.45 & 42.40 & التجريبية بعدي & الوعي الذاتي & البعدي \\
\hline & & & 4.97 & 40.33 & الضابطة بعدي & بالعواطف & \\
\hline \multirow[t]{2}{*}{0.011} & 28 & 2.714 & 1.11 & 20.67 & التجريبية بعدي & التعاطف & \\
\hline & & & 1.54 & 19.33 & الضابطة بعدي & & \\
\hline \multirow[t]{2}{*}{0.743} & 28 & 3,43 & 3.13 & 22.69 & التجريبية بعدي & ادارة العواطف & \\
\hline & & & 3.13 & 23.0 & الضابطة بعدي & & \\
\hline \multirow[t]{2}{*}{0.000} & 28 & 4.005 & 1.11 & 18.33 & التجريبية بعدي & الدافعية & \\
\hline & & & 1.50 & 16.40 & الضابطة بعدي & & \\
\hline \multirow[t]{2}{*}{0.205} & 28 & $1.299-$ & 4.06 & 25.47 & التجريبية بعدي & المهارات الاجتماعية & \\
\hline & & & 2.49 & 27.07 & الضابطة بعدي & & \\
\hline \multirow[t]{2}{*}{0.437} & 28 & 0.789 & 12.36 & 129.46 & التجريبية بعدي & الدرجة الكلية & \\
\hline & & & 8.93 & 126.28 & الضابطة بعدي & & \\
\hline
\end{tabular}

يتضح من نتائج جدول (5) أنه لا توجد فروق ذات دلالة إحصائية على مقياس الذكاء العاطفي بين المجموعتين التجريبية والضابطة في القياس

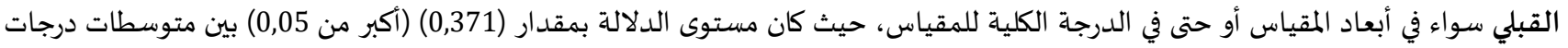

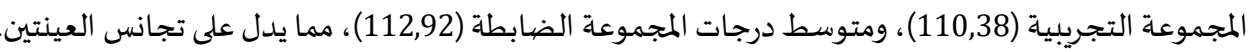
أما بالنسبة للفروق في القياس البعدي بين المجموعتين التجريبية والضابطة التضح المبح ما يلي:

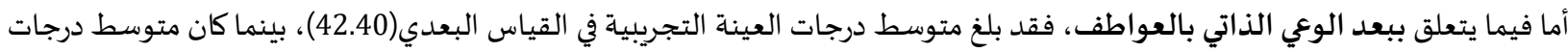

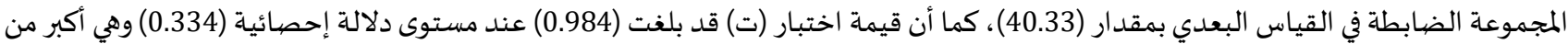

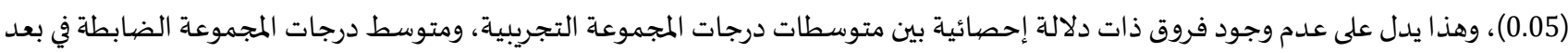

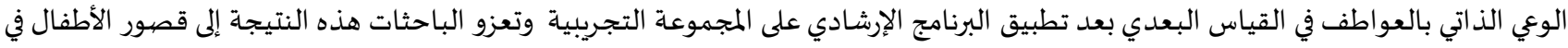

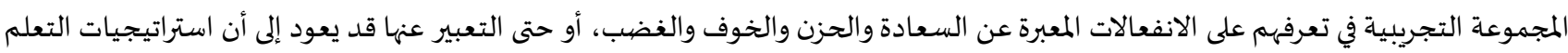
التعاوني التي هدفت إلى تنمية جانب الوعي بالعواطف عند الأطفال، اقتصرت على (الرسم الجماعي، اللعب التمثيلي، وتأليف القصائ، التصائ والتخييل

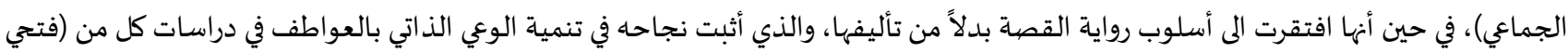

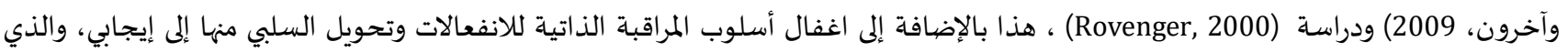

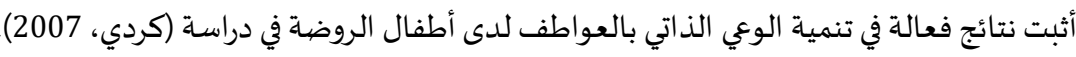

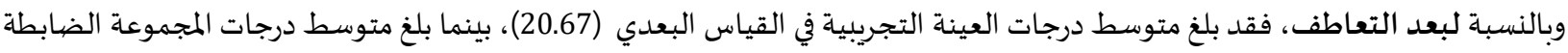

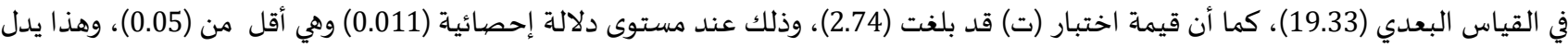

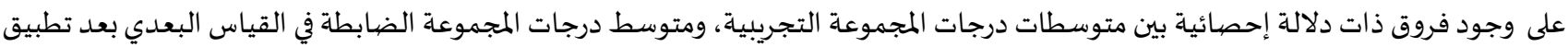

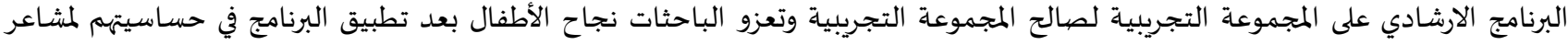

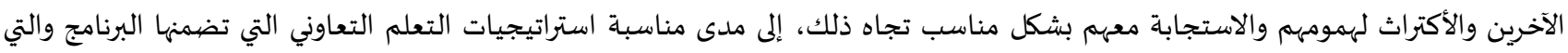

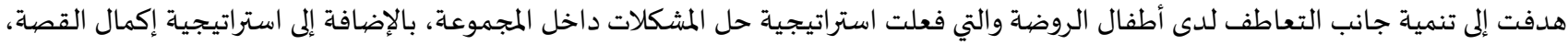

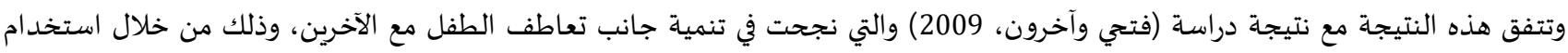


أسلوب القصة، كما نجحت دراسـة (كردي، 2007) في تنمية استبصار أطفال الروضة بمشاعر الآخرين من خلال استخدام أسلوب حل المشكلات، هذا

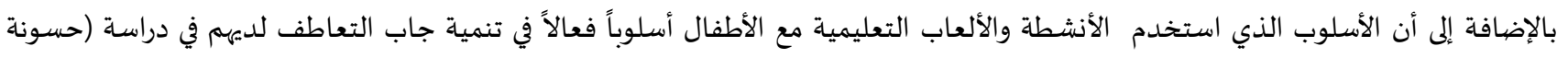

وسعيد، 2001).

أما بعد إدارة العواطف، فقد دلت نتائج الدراسة إلى أن متوسط درجات العينة التجريبية في القياس البعدي على هذا البعد قد بلغ (22.60)،

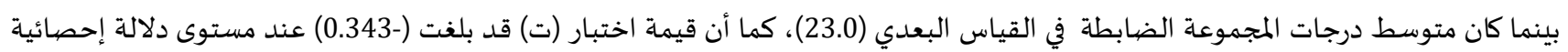

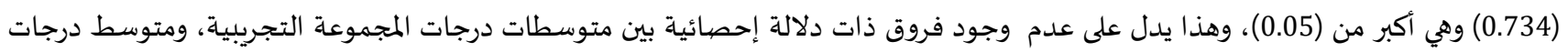
المجموعة الضابطة في بعد إدارة العواطف في القياس البعدي البعدي بعد تطبيق البرنامج الارشادي على المجموعة التجريبية وتعزو الباحثات عدم تميز المجموعة التجريبية عن المجموعة الضابطة في القياسين وبالأخص (البعدي) في زيادة قدرة الطفل على التحكم بالانفعالات وضبط الديط الاستجابات الذاتياة

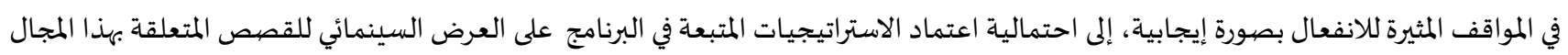
ومناقشتها عوضاً عن روايتها والتعامل شكل أكثر فاعلية في مناقشتها، في حين نجحت دراسات أخرى، مثل دراسة كل من (فتحي وآخرون، 2009) ودراسة فovenger, 2000)

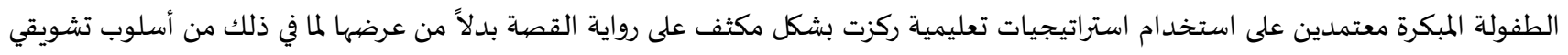

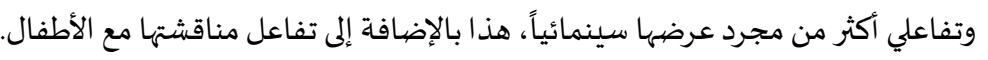

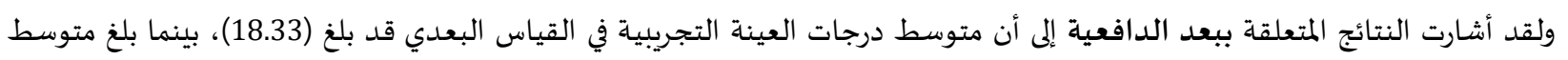

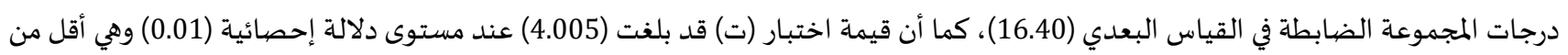

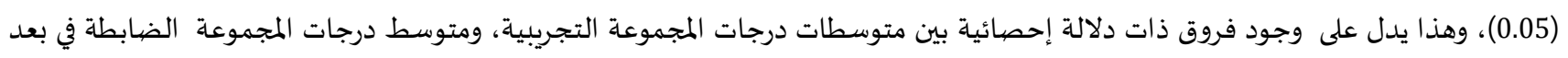

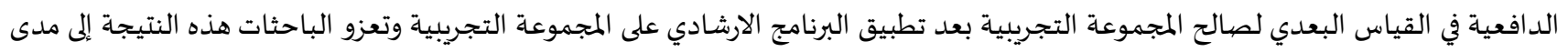

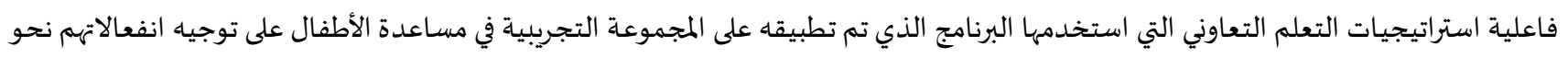

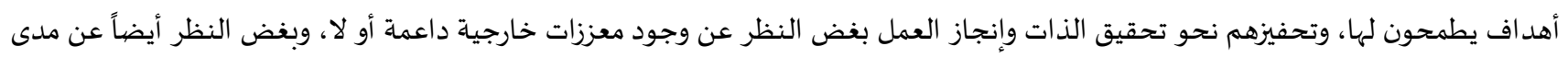

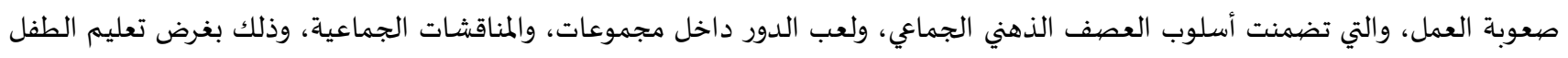

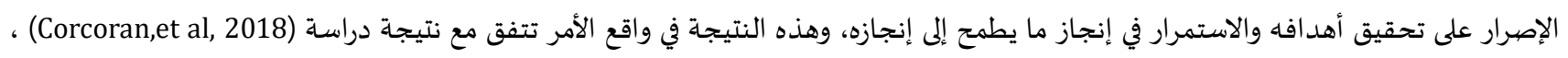

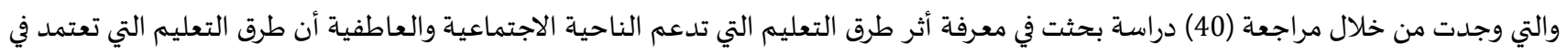

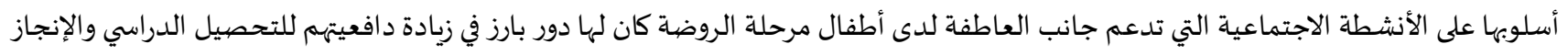

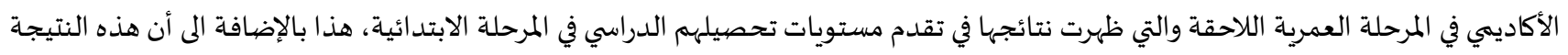

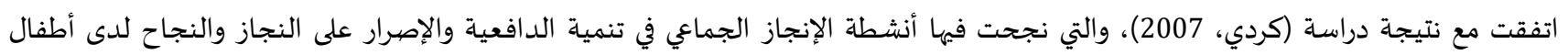
الروضية.

وفي بعد المهارات الاجتماعية، فقد بلغ متوسط درجات العينة التجريبية في القياس البعدي(25.47)، في حين أن متوسط درجات المجموعة

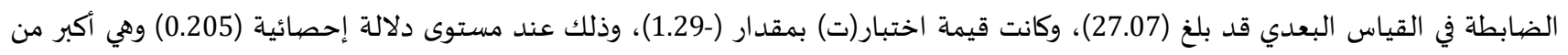

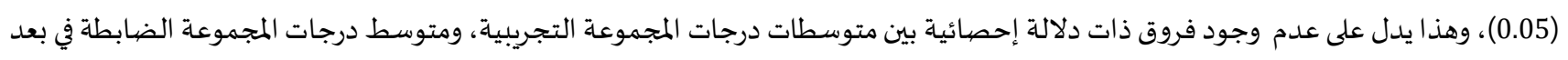

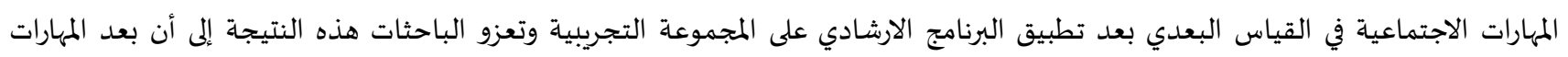

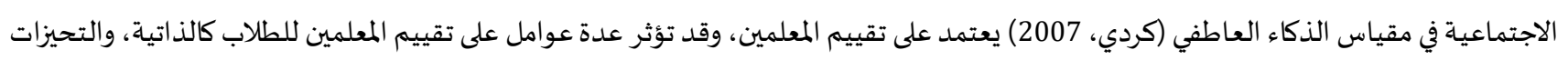

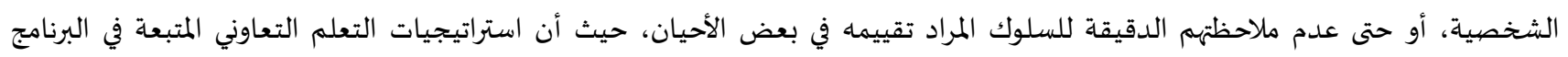

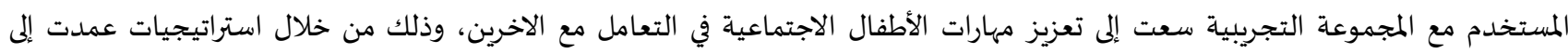

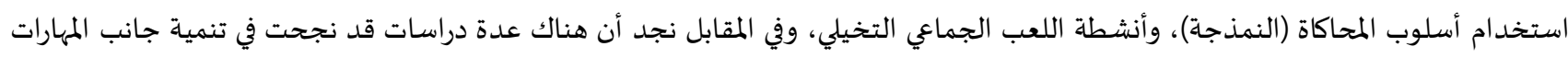

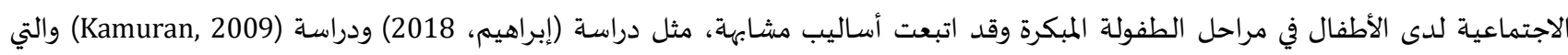

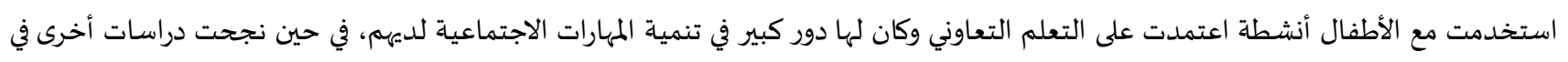
تنمية جانب المهارات الاجتماعية عند أطفال الروضة من خلال استخدام أساليب محددة كأسلوب رواية القصص، مثل دراعل دراسة (فتحي وآخرون،

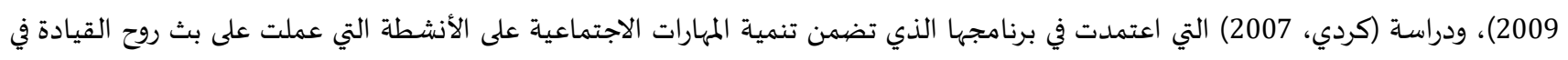
الأطفال والتفاعل الإيجابي مع الاخرين. وفيما يتعلق بنتائج الدراسة حول الفروقات بين متوسطات الإنئ الدرجة الكلية للمقياس الذكاء العاطفي لدى المجموعتين التجريبية والضابطة في

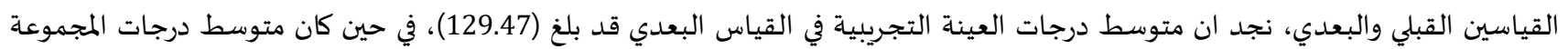


الضابطة في القياس البعدي بمقدار (126.29)، وكانت قيمة اختبار (ت) تساوي(0.789)، وذلك عند مستوى دلالة إحصائية (0.437) وهي أكبر من

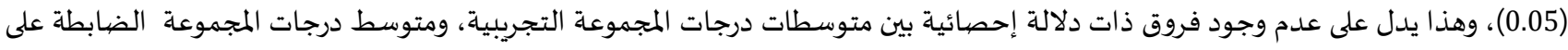

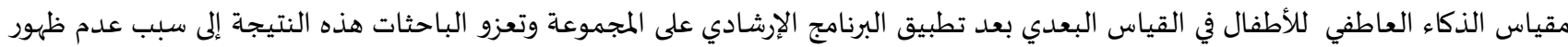

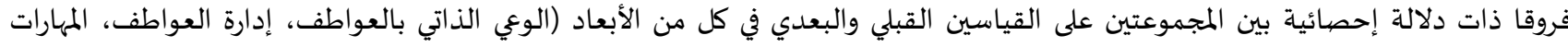

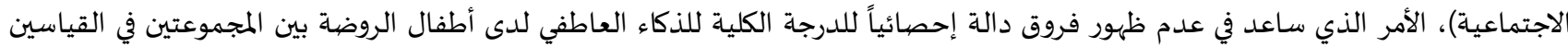

القبلي والبعدي. الفرض الثاني: توجد فروق ذات دلالة إحصائية بين متوسطي درجات القياسين القبلي والبعدي للمجموعة التجريبية على مقياس الذكاء العاطفي لدى اطفال الروضة بمدينة مكة المكرمة.

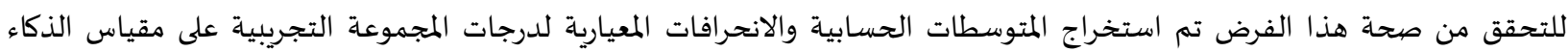

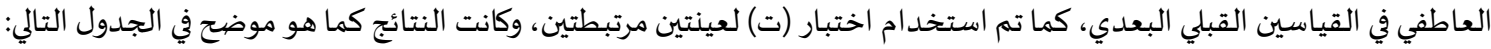

\begin{tabular}{|c|c|c|c|c|c|c|}
\hline الدلالة & درجة الحرية & قيمة (ت) & المعياري & المتوسط & القياس & البعد البعد \\
\hline \multirow[t]{2}{*}{0.001} & 14 & $-4.287-$ & 4.51 & 34.26 & القياس القبلي & الوعي الذاتي بالعواطف \\
\hline & & & 6.44 & 42.40 & القياس البعدي & \\
\hline \multirow[t]{2}{*}{0.005} & 14 & $-3.374-$ & 1.83 & 18.73 & القياس القبلي & التعاطف \\
\hline & & & 1.11 & 20.67 & القياس البعدي & \\
\hline \multirow[t]{2}{*}{0.79} & 14 & $-.355-$ & 2.28 & 22.30 & القياس القبلي & ادارة العواطف \\
\hline & & & 3.35 & 22.69 & القياس البعدي & \\
\hline \multirow[t]{2}{*}{0.000} & 14 & $\begin{array}{l}-7.903- \\
\end{array}$ & 1.35 & 15.40 & القياس القبلي & الدافعية \\
\hline & & & 1.11 & 18.33 & القياس البعدي & \\
\hline \multirow[t]{2}{*}{0.000} & 14 & $-6.533-$ & 4.50 & 19.13 & القياس القبلي & المهارات الاجتماعية \\
\hline & & & 4.06 & 25.46 & القياس البعدي & \\
\hline \multirow[t]{2}{*}{0.000} & 14 & $\begin{array}{l}-5.836- \\
\end{array}$ & 8.67 & 110.38 & القياس القبلي & الدرجة الكلية \\
\hline & & & 11.9 & 130.15 & القياس البعدي & \\
\hline
\end{tabular}

يتضح من جدول (6) ان نتائج اختبار (ت) للمقارنة الزوجية بين متوسطات درجات المجموعة التجريبية في القياسين القبلي والبعدي على مقياس

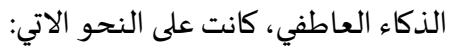

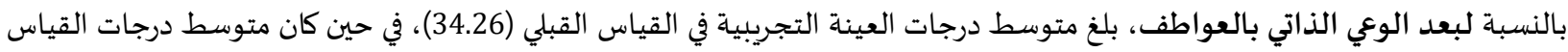

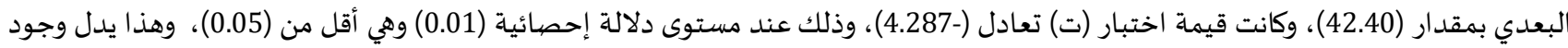

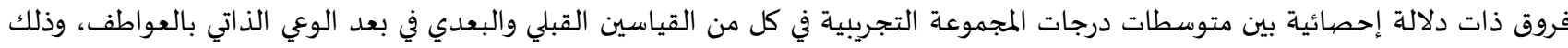

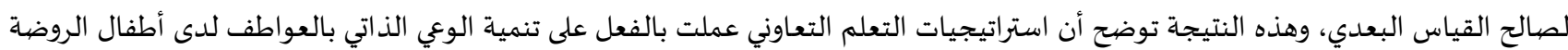
(كالرسم الجماعي، اللعب التمثيلي، وتأليف القصص، والتخييل الجماعي)، وتتفق هذه النتيجة مع دراسة كل من (فتحي وآخرون، 2009) ودراسة ( (Rovenger, 2000 اتفقت هذه النتيجة مع دراسة (حسونة وسعيد، 2001) التي استخدمت الأنشطة والألعاب التعليمية الجماعية مع الأطفال، والتي نجحت في تنمية الوعي الذاتي بالعواطف لدى الأطفال.

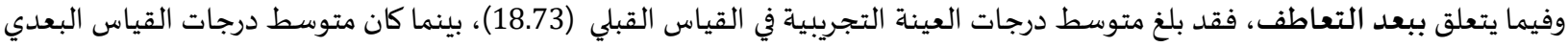

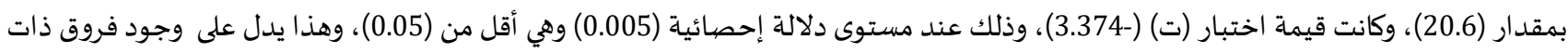

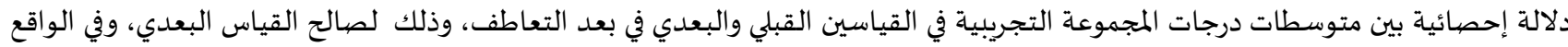

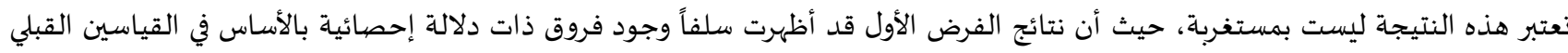

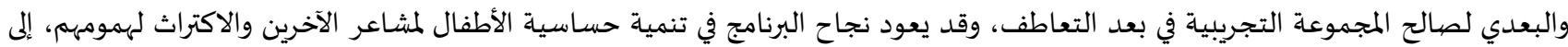

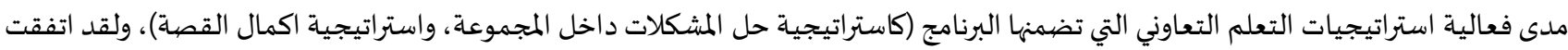

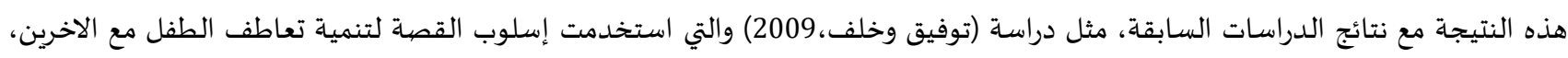

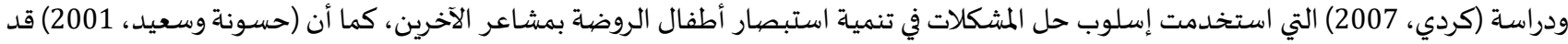
نجحوا في استخدم الأنشطة والألعاب التعليمية مع الأطفال في تنمية جاب الماب التعاطف لديهيم. 
وفيما يخص بعد إدارة العواطف، فقد اشارت النتائج إلى أن متوسط درجات العينة التجريبية في القياس القبلي قد بلغ (22.30)، بينما كان

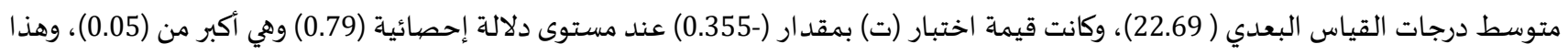

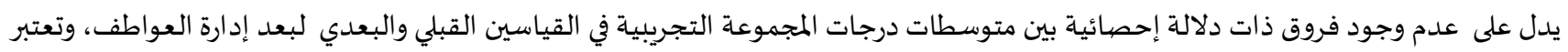

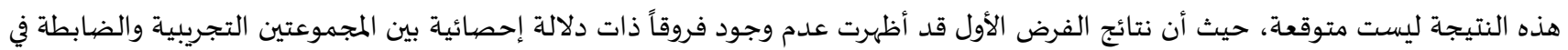

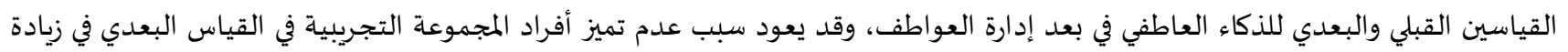

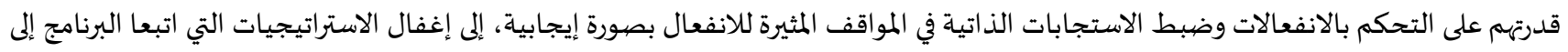

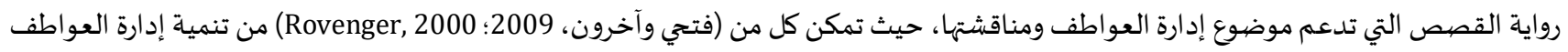

لدى طفل الروضية من خلال رواية القصة و مناقشتها مع الأطفال.

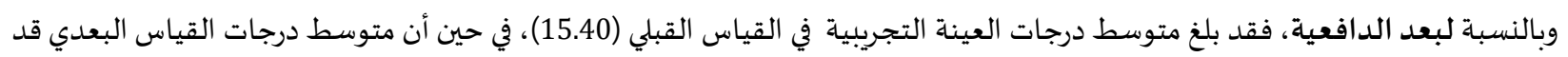

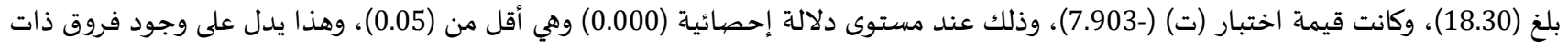

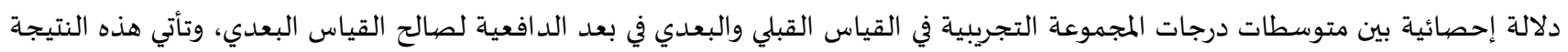

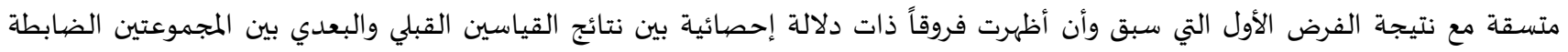

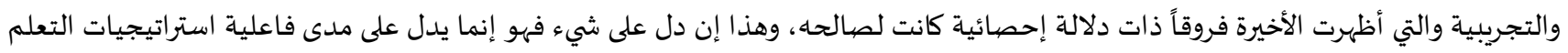

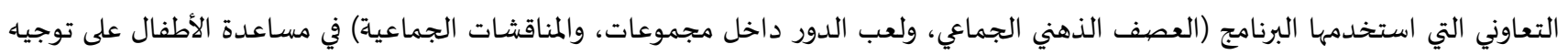

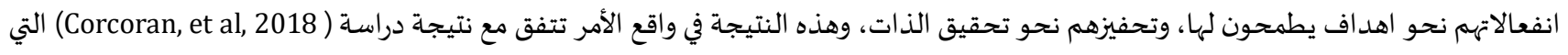

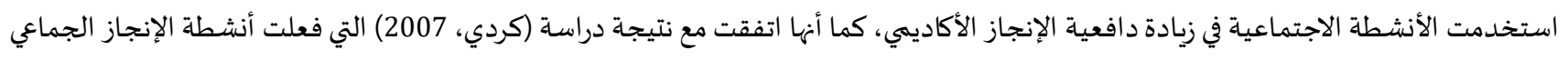

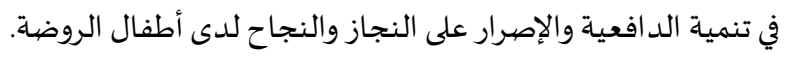

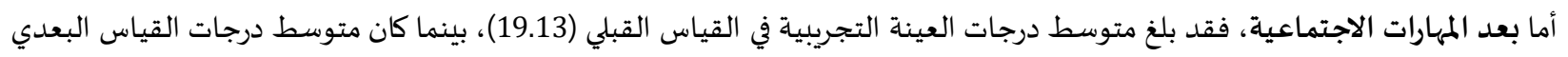

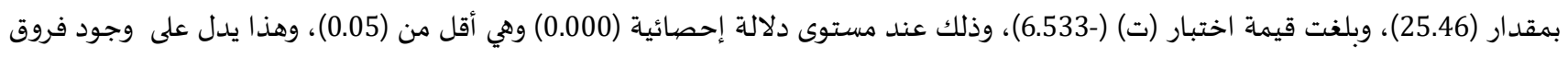

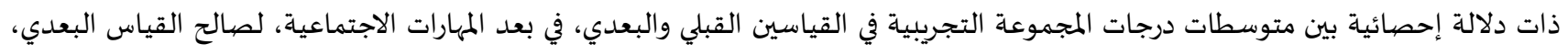

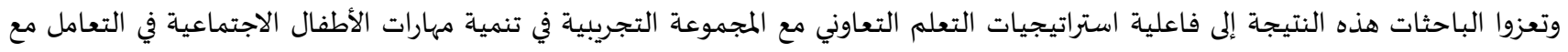
الاخرين، والتي استخدمت إسلوب المحاكاة (النمذجة)، وانشطة اللعب الجماعي التخيلي، واتفقت هذه النتيجة ومع النداتئه نتائج دراسة (إبراهيم، 2018)

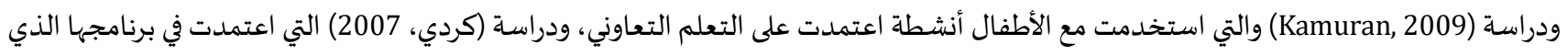

تضمن تنمية المهارات الاجتماعية على أنشطة تنمية التفاعل الإيجابي مع الاخرين.

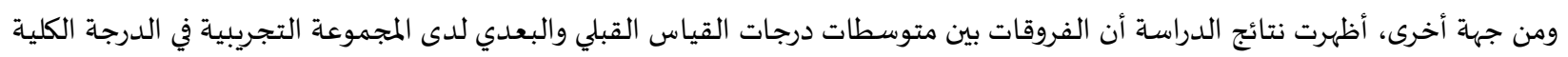
لمقياس الذكاء العاطفي كانت فروقات دالة إحصائياً، فقد بلغ متوسط درجات العينة التجريبية في القياس القبلي (110.38)، بينما كان متوسط دئيات درجات

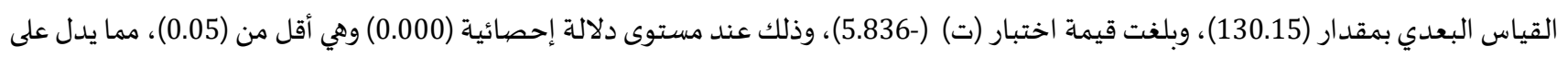

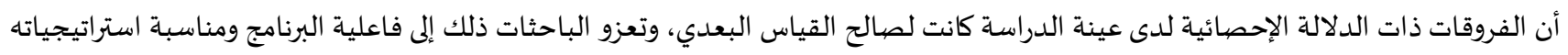

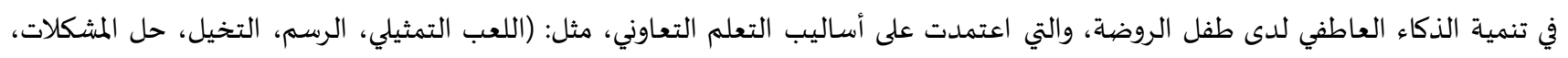

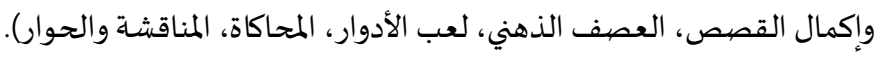

$$
\text { التوصيات والمقترحات }
$$

تعد مرحلة الروضة الأساس الأول للعملية التعليمية، وقد أصبح لها دوراً بارزاً في ظل التربية الحديثة، حيث أصبح هناك اهتمام بارز بتعليم

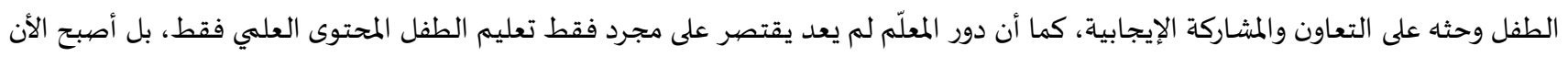

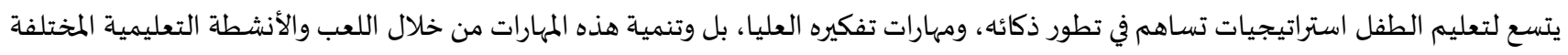

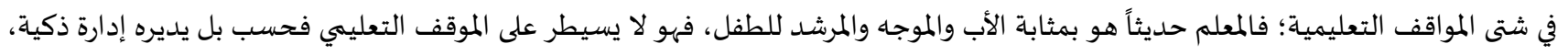

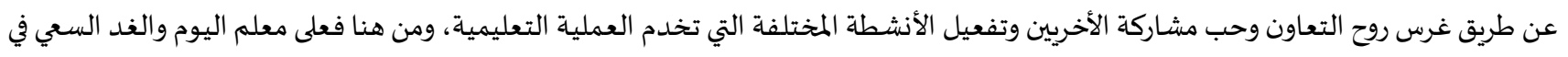

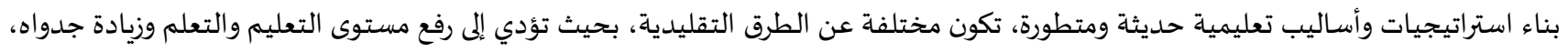

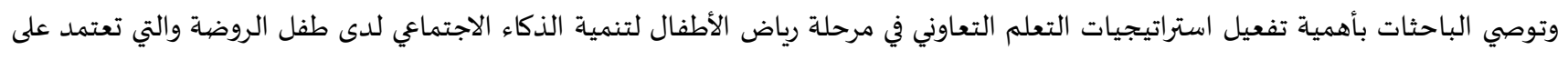

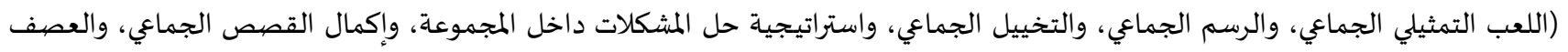

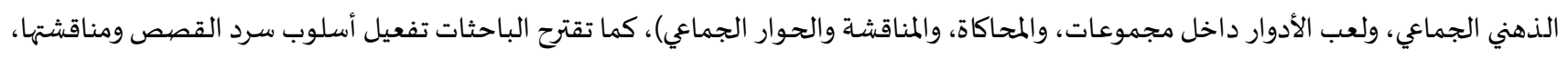

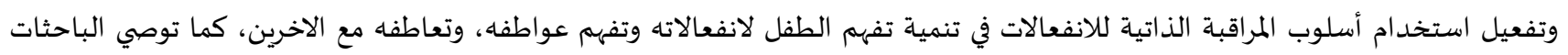


معلمات رياض الأطفال بالعمل على تنمية الدافعية وروح الإنجاز لدى الأطفال، وأخيراً تقترح الباحثات تجريب استراتيجيات مختلفة من استراتيجيات

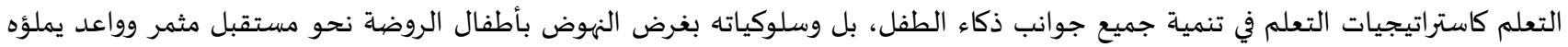

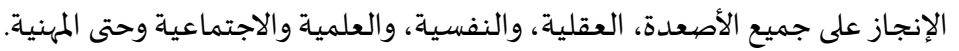

أولاً: المراجع العربية:

1. إبراهيم، ج. (2018). التعلم التعاوني ودوره في تنمية مهارات التوافق الاجتماعي للدى طفل ما قبل المدرسة. مجلة أسيوط: كلية التربية، 34 (11): $.420-348$

2. إبراهيم، س. (2011). الذكاء الوجد/ني لطفل الروضية الموهوب من منظورتربوي. عمَان: الوراق للنشر والتوزيع.

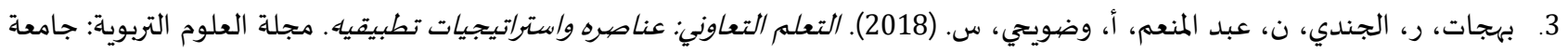

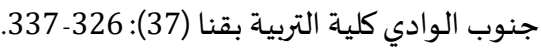

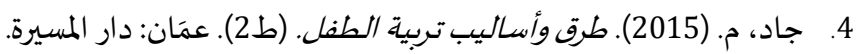

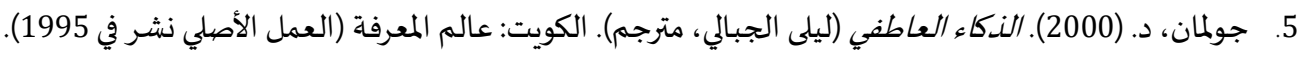

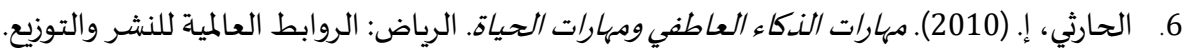
7. حافظ، ن. (2019).كيف تنسي ذكاء /بنك العاطفي؟. القاهرة: مكتبة الأنجلو المصريرية. 8.

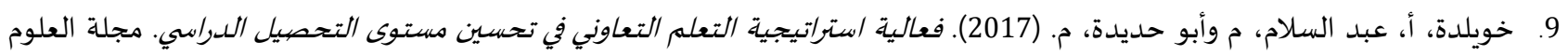

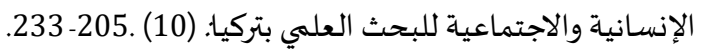

10. رفاعي، ع. (2012). التعلم النشط المفهوم والاستراتيجيات وتقويم نواتج التعله. القاهرة: دار الجامعة الجديدة.

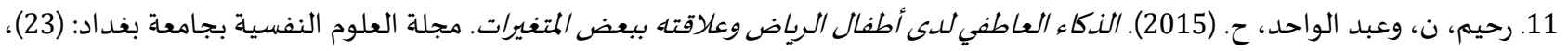
375-346

12. الزكي، م. (2010). نبذه عن التعلم التعاوني. مجلة التطوير التربوي، وزارة التربية والتعليم: 8 (54) ، 12- 20 (2007)

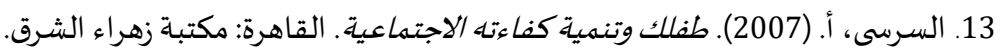

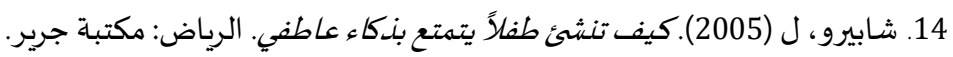
15. شحاته، ح، والنجار، ز. (2003). معتمر المصيطلحات التربوية والنفسية. القاهرة: لدار المصرية اللبنانياة.

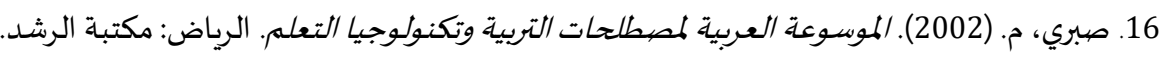
17. عبد المعطي، ع. (2000). أطفالنا خطة عملية للتوبية الجمالية سلوكا وأخلاق. (ط2). القاهرة: دار التوزيع والنشر الإسلامية.

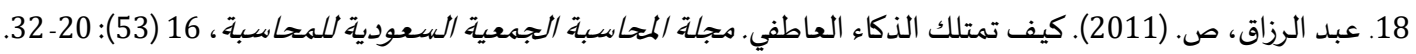
19. العتيبي، س. (2016). فاعلية استخدام استراتيجية التعلم النشط في تدريس مقررات التربية الإسلامية على تحصيل طلاب المرحلة الثانوية بمنطقة مكة المككرمة واتجاهات المعلمين نحوه. (رسالة دكتوراه غير منشورة)، الجامعة الإسلامية، المدينة المنورة.

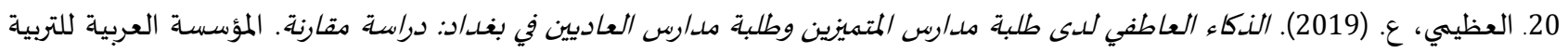

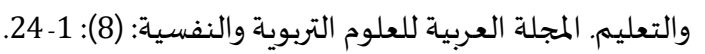

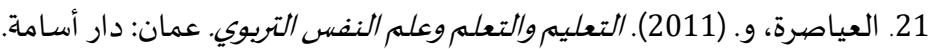

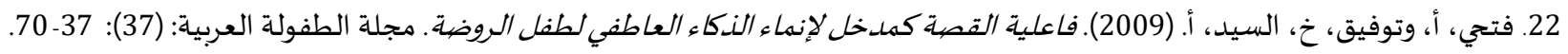

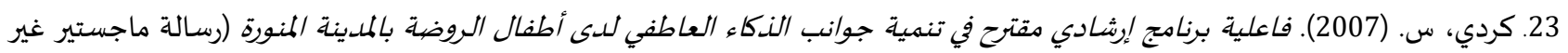
منشورة)، جامعة طيبة، المدينة المنورة. 24. محمد، ع. (2005). المنهج النبوي في تربية الطفل. القاهرة: دار ألفا للنشر. 25. مصطفى، ف. (2002). مهارات التفكير في مراحل التعليم العام. القاهرة: دار الفكر العربي.

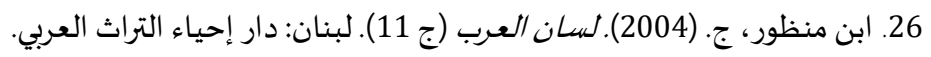


1. Corcoran, R., Cheung, A., Kim, E., \& Xie, C. (2018). Effective universal school based social and emotional learning programs for improving academic achievement: A systematic review and meta- analysis of 50 years of research, Educational Research Review, 25: 56- 72, https://doi.org/10.1016/j.edurev.2017.12.001.

2. Kamuran, T. (2009). The effects of coperative learning on preschoolers' mathematics problem- solving ability, Educational Studies in Mathematics, 72(3): 325- 340, https://doi.org/10.1007/s10649-009-9197-x.

3. Rovenger,K, J. (2000). Fostering emotional intelligence, School Library Journal, 46(12): 40 - 45

4. Torres, M., Domitrovich, C., \& Bierman, K. (2015). Preschool interpersonal relationships predict kendergarten achievement: Mediated by gains in emotion knowledge, J Applide Developmental Psychology, 39: 44-52, https://doi.org/10.1016/j.appdev.2015.04.008 
المجلة الدولية للدراسـات التربوية والنفسية

International Journal of Educational \& Psychological Studies (EPS)

Journal Homepage: https://www.refaad.com/views/EPSR/Home.aspx

www.refaad.com

ISSN: 2520-4149 (Online) 2520-4130 (Print)

\title{
The effectiveness of a program based on collaborative learning strategies to develop emotional intelligence in kindergarten children in Mecca city
}

\author{
${ }^{1}$ Swzan Sadaqah Basyouni, ${ }^{2}$ Omniah Abdulkader Alsharif, ${ }^{3}$ Dalal Hdian AlThowaibi \\ ${ }^{4}$ Samah Eid Al Harbi, ${ }^{5}$ Fatemah Adnan Al Shakhs \\ 1 Prof. of Counselling and Mental Health, Umm Al- Qura University, KSA \\ 2,3 Lecturer of Psychology, Umm Al- Qura University, KSA \\ ${ }^{4}$ Lecturer of Psychology, Taibah University, KSA \\ 5 PhD Researcher in Psychology, Umm Al-Qura University, KSA \\ ${ }^{1}$ ssbasuoni@uqu.edu.sa,2 Monyatee-2008@hotmail.com,33 Dalal0855@gmail.com, \\ ${ }^{4}$ samahlayan@gmail.com, ${ }^{5}$ venus-787@hotmail.com
}

Received : 23/7/2020 Revised : 11/8/2020 Accepted : 27/9/2020 DOI : https://doi.org/10.31559/EPS2021.9.2.12

\begin{abstract}
The study aims at identifying the effectiveness of a program based on collaborative learning strategies within the classroom in the development of emotional intelligence in kindergarten children in Mecca. The sample consisted of (30) children (boys and girls) at the Primary education, ages 5-6 years, selected in a random way, applied to them the measure of emotional intelligence before and after the use of a program based on cooperative learning strategies: pretend play, drawing, imagining, problem solving, story completion, brainstorming, role-playing game, simulation, discussion and dialogue). The results indicated that the program was effective in the development of emotional intelligence in the sample of children: statistically significant differences emerged between the experimental and control groups in the pre and post measures of emotional intelligence in favor of the experimental group, in the two dimensions (motivation and empathy). There were no statistically significant differences in the overall degree of the scale and in dimensions (self-awareness of emotions, emotion management, and social skills). (There were significant differences in the dimension measurement of the experimental group in the overall degree of the measure of emotional intelligence, and in dimensions (self-awareness of emotions, empathy, motivation, social skills), except after (emotion management).
\end{abstract}

Keywords: Cooperative Learning Strategies; Emotional Intelligence; Kindergarten Children.

\section{References:}

1. 'bd Alm'ty, 'E. (2000). Atfalna Khth 'mlyh Lltrbyh Aljmalyh Slwka Wakhlaq. (T2). Alqahrh: Dar Altwzy' Walnshr Aleslamyh.

2. 'bd Alrzaq, S. (2011). Kyf Tmtlk Aldka' Al'atfy. Mjlt Almhasbh Aljm'yh Als'wdyh Llmhasbh, 16 (53): 20- 32.

3. Al'tyby, S. (2016). Fa'lyt Astkhdam Astratyjyh Alt'Im Alnsht Fy Tdrys Mqrrat Altrbyh Aleslamyh 'la Thsyl Tlab Almrhlh Althanwyh Bmntqh Mkh Almkrmh Watjahat Alm'lmyn Nhwh. (Rsalt Dktwrah Ghyr Mnshwrh), Aljam'h Aleslamyh, Almdynh Almnwrh.

4. Al'yasrh, W. (2011). Alt'lym Walt'Im W'elm Alnfs Altrbwy. 'man: Dar Asamh.

5. Al'zymy, '. (2019). Aldka' Al'atfy Lda Tlbt Mdars Almtmyzyn Wtlbt Mdars Al'adyyn Fy Bghdad: Drash Mqarnh. Alm'ssh Al'rbyh Lltrbyh Walt'lym. Almjlh Al'rbyh Ll'lwm Altrbwyh Walnfsyh: (8): 1- 24.

6. Bhjat, R, Aljndy, N, 'bd Almn'm, A, Wdwyhy, S. (2018). Alt'lm Alt'awny: 'nasrh Wastratyjyat Ttbyqyh. Mjlt Al'Iwm Altrbwyh: Jam't Jnwb Alwady Klyt Altrbyh Bqna (37): 326- 337.

7. Ebrahym, J. (2018). Alt'Im Alt'awny Wdwrh Fy Tnmyt Mharat Altwafq Alajtma'y Lda Tfl Ma Qbl Almdrsh. Mjlt Asywt: Klyh Altrbyh, 34 (11): 348- 420.

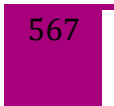

المجلة الدولية للدراسات التربوية والنفسية- المجلد9، العدد2- 2021، ص: 552-568 
8. Ebrahym, S. (2011). Aldka' Alwjdany Ltfl Alrwdh Almwhwb Mn Mnzwr Trbwy. 'mán: Alwraq Llnshr Waltwzy'.

9. Jad, M. (2015). Trq Wasalyb Trbyh Altfl. (T2). 'mán: Dar Almsyrh.

10. Jwlman, D. (2000). Aldka' Al'atfy (Lyla Aljbaly, Mtrjm). Alkwyt: 'alm Alm'rfh (Al'ml Alasly Nshr Fy 1995).

11. Hafz, N. (2019). Kyf Tnmy Dka' Abnk Al'atfy? Alqahrh: Mktbt Alanjlw Almsryh.

12. Fthy, A, Wtwfyq, Kh, Alsyd, A. (2009). Fa'lyt Alqsh Kmdkhl Lenma' Aldka' Al'eatfy Ltfl Alrwdh. Mjlt Altfwlh Al'rbyh: (37): 37- 70.

13. Alharthy, E. (2010). Mharat Aldka' Al'atfy Wmharat Alhyah. Alryad: Alrwabt Al'almyh Llnshr Waltwzy'.

14. Hsnyn, H. (2007). Tryqt Hl Almshklat. 'mán: Dar Mjdlawy.

15. Khwyldh, A, 'bd Alslam, M Wabw Hdydh, M. (2017). F'ealyh Astratyjyh Alt'lm Alt'awny Fy Thsyn Mstwa Althsyl Aldrasy. Mjlt Al'lwm Alensanyh Walajtma'eyh Llbhth Al'lmy Btrkya: (10) .205- 233.

16. Krdy, S. (2007). Fa'lyt Brnamj Ershady Mqtrh Fy Tnmyt Jwanb Aldka' Al'atfy Lda Atfal Alrwdh Balmdynh Almnwrh (Rsalt Majstyr Ghyr Mnshwrh), Jam't Tybh, Almdynh Almnwrh.

17. Mhmd, '. (2005). Almnhj Alnbwy Fy Trbyt Altfl. Alqahrh: Dar Alfa Llnshr.

18. Abn Mnzwr, J. (2004). Lsan Al'rb (J 11). Lbnan: Dar Ehya' Altrath Al'rby.

19. Mstfa, F. (2002). Mharat Altfkyr Fy Mrahl Alt'lym Al'eam. Alqahrh: Dar Alfkr Al'rby.

20. Rfa'y, '. (2012). Alt'lm Alnsht Almfhwm Walastratyjyat Wtqwym Nwatj Alt'lm. Alqahrh: Dar Aljam'h Aljdydh.

21. Rhym, N, W'bd Alwahd, H. (2015). Aldka' Al'atfy Lda Atfal Alryad W'laqth Bb'd Almtghyrat. Mjlt Al'lwm Alnfsyh Bjam't Bghdad: (23), 346-375.

22. Sbry, M. (2002). Almwsw'h Al'rbyh Lmstlhat Altrbyh Wtknwlwjya Alt'lm. Alryad: Mktbh Alrshd.

23. Shabyrw, L (2005). Kyf Tnsh' Tflaan Ytmt' Bdka' 'atfy. Alryad: Mktbh Jryr.

24. Shhath, H, Walnjar, Z. (2003). M'jm Almstlhat Altrbwyh Walnfsyh. Alqahrh: Ldar Almsryh Allbnanyh.

25. Alsrsa, A. (2007). Tflk Wtnmyh Kfa'th Alajtma'yh. Alqahrh: Mktbh Zhra' Alshrq.

26. Alzky, M. (2010). Nbdh 'n Alt'Im Alt'awny. Mjlt Alttwyr Altrbwy, Wzarh Altrbyh Walt'lym: 8 (54), 12- 20. 